\title{
The NDP52/CALCOCO2 selective autophagy receptor controls processing body disassembly
}

inflammatory cytokine transcripts / Kaposi’s sarcoma-associated herpesvirus / NDP52 /

processing bodies / selective autophagy

Carolyn-Ann Robinson ${ }^{1,2,3,4}$, Gillian K. Singh ${ }^{1,4}$, Elizabeth L. Castle ${ }^{1}$, Bre Q. Boudreau ${ }^{1}$, Jennifer

A. Corcoran ${ }^{1,2,3,5}$

${ }^{1}$ Department of Microbiology \& Immunology, Dalhousie University, Halifax, NS, Canada

${ }^{2}$ Microbiology, Immunology \& Infectious Diseases Department, University of Calgary, Calgary, AB, Canada.

${ }^{3}$ Charbonneau Cancer Research Institute, University of Calgary, Calgary, AB, Canada.

${ }^{4}$ Equal Contribution

${ }^{5}$ Corresponding Author 


\section{Abstract}

2 Processing bodies (PBs) are cytoplasmic ribonucleoprotein granules that control inflammation by

3 silencing or degrading labile messenger RNAs (mRNAs) that encode inflammatory molecules.

$4 \quad$ PBs often disassemble in response to virus infection, which correlates with increased synthesis of

5 inflammatory proteins. We previously showed that the Kaposi’s sarcoma-associated herpesvirus

6 (KSHV) KapB protein causes PB disassembly. Here, we reveal that KapB-mediated PB

7 disassembly depends on the canonical autophagy genes $\operatorname{Atg} 5$ and $\operatorname{Atg} 14$ or the selective

8 autophagy receptor NDP52/CALCOCO2. Moreover, KapB expression increased inflammatory

9 transcripts levels and this effect was also dependent on canonical autophagy and NDP52.

10 Stimulating autophagy with the mTOR inhibitor Torin-1 also increased cytokine mRNA and

11 required ATG5 and NDP52 to mediate PB disassembly. These studies reveal a new role for

12 NDP52 in regulating inflammatory responses by promoting PB turnover and the concomitant

13 synthesis of inflammatory molecules. 
Introduction

17 Under basal conditions, autophagic activity ensures the continuous recycling of cellular

18 resources and the clearance of damaged macromolecular complexes and organelles, maintaining cellular homeostasis and acting as an intracellular quality control system (Green et al, 2011; Klionsky et al, 2012; Morishita \& Mizushima, 2019; Levine et al, 2008). Various changes to the cellular microenvironment, including nutrient scarcity, hypoxia, and endoplasmic reticulum (ER) stress can drive autophagy and degradation of damaged organelles (e.g mitochondria, peroxisomes), protein complexes (e.g. focal adhesion complexes), or other targets in a selective manner (Maiuri \& Kroemer, 2015; Mizushima et al, 2010; Balgi et al, 2009; Kenific et al, 2016; Sargsyan et al, 2015; Tripathi et al, 2016; Dunn et al, 2005; Yao \& Klionsky, 2016). In selective autophagy, target cargo is selected for degradation either directly, by binding to lipidated microtubule associated protein 1 light chain 3 (LC3) protein (LC3-II), or indirectly via molecular bridges termed selective autophagy receptors (SARs). Some of the best characterized SARs include p62/SQSTM1, valosin containing protein (VCP), optineurin (OPTN), neighbor of BRCA1 gene 1 (NBR1), and nuclear dot protein 52 (NDP52/calcium binding and coiled-coil domain protein, CALCOCO2) (Zaffagnini \& Martens, 2016). OPTN, p62, NDP52, and NBR1 are members of the sequestosome-like family and contain several conserved motifs including a LC3-interacting region (LIR) and a ubiquitin-binding domain (UBD) (Ichimura et al, 2008; Noda et al, 2010; Birgisdottir et al, 2013; Noda et al, 2008). The selection of cargo for degradation can occur in a ubiquitin-dependent or -independent manner, although ubiquitin modification is believed to enhance cargo recruitment to autophagosomes (Rogov et al, 2014).

37 SARs play important homeostatic roles in maintaining, and at times magnifying, the turnover of organelles and aggregates which facilitates cell survival in response to environmental changes 
39 (Maiuri \& Kroemer, 2015; Mizushima et al, 2010; Balgi et al, 2009; Kenific et al, 2016;

Sargsyan et al, 2015; Tripathi et al, 2016; Dunn et al, 2005; Yao \& Klionsky, 2016).

41

42 SARs also play important roles in fine-tuning innate immune responses by targeting key signaling platforms for degradation (Chen et al, 2016; Du et al, 2018; Jin et al, 2017; Prabakaran et al, 2018; Yang et al, 2017; He et al, 2019). For example, NDP52 is required for the autophagic degradation of interferon regulatory factor 3 (IRF3) and mitochondrial antiviral signaling protein (MAVS), which supports the resolution phase of type I interferon signaling

47 (Wu et al, 2020) (Seth et al, 2005; Jin et al, 2017). Both pro and antiviral roles have been attributed to SARs (Sumpter \& Levine, 2011; Ahmad et al, 2018) and viruses can both enhance or limit SAR function accordingly, promoting their replication (Mohamud et al, 2019). Kaposi's sarcoma-associated herpesvirus (KSHV) is the infectious cause of two B-cell

51 malignancies and the endothelial cell cancer, Kaposi's sarcoma (KS), which is typified by

52 aberrant angiogenesis, tortuous leaky blood vessels, and inflammation (Cesarman et al, 1995;

53 Chang et al, 1994; Soulier et al, 1995). Infection with KSHV has two forms, a latent and a lytic 54 phase and it is the latent phase that predominates in KS tumours (Decker et al, 1996; Staskus et 55 al, 1997; Broussard \& Damania, 2020). Like many viruses, KSHV manipulates the autophagic 56 machinery. During latency, the viral FLICE inhibitory protein (v-FLIP) binds Atg3 to suppress

57 the LC3 lipidation process during autophagosome biogenesis (Lee et al, 2009). KSHV also

58 expresses a viral cyclin D homolog (v-cyclin), that triggers DNA damage that that leads to 59 autophagy and cellular senescence (Leidal et al, 2012), facilitating the production and non60 conventional secretion of pro-inflammatory cytokines such as IL-1 $\beta$, IL-6 and IL-8 (Young et al, 61 2009). Together, KSHV manipulation of autophagic flux prevents xenophagy, limits interferon 
62 responses and enhances inflammatory cytokine production. Precisely how KSHV fine tunes

63 autophagy during latency to balance proviral and antiviral activities and promote chronic viral

64 infection is not clear.

65

66 Processing bodies (PBs) are ubiquitous, cytoplasmic, ribonucleoprotein (RNP) granules that

67 regulate expression of many cytokine RNA transcripts, making them important sites of

68 inflammatory control. PBs contain enzymes involved in mRNA turnover, including those that

69 mediate decapping (Dcp2; co-factors Dcp1a and Edc4/Hedls), 5'-3' exonucleolytic degradation

70 (5'-3' exonuclease Xrn1 and RNA helicase Rck/DDX6) and some components of the RNA-

71 induced silencing complex (Cougot et al, 2012; Hubstenberger et al, 2017; Corbet \& Parker,

72 2019; Youn et al, 2018; Riggs et al, 2020; Mohamud et al, 2019; Luo et al, 2018). mRNAs are

73 routed to PBs for decay and/or repression by RNA-binding proteins (RBPs) through recognition

74 of common sequence elements (Hubstenberger et al, 2017). AU-rich elements (AREs) are

75 destablilizing RNA regulatory elements found in the 3' untranslated regions of $\sim 8 \%$ of cellular

76 transcripts that are responsible for targeting RNAs to PBs (Barreau et al, 2005; Bakheet et al,

77 2018; García-Mauriño et al, 2017). When bound by destabilizing RBPs, ARE-containing RNAs

78 are directed to PBs and suppressed (Maitra et al, 2008; Lai et al, 1999; Lai \& Blackshear, 2001).

79 Our group and others showed that microscopically visible PBs correlate with the constitutive

80 turnover or translational suppression of ARE-mRNAs; when PBs are dispersed, this suppression

81 is reversed (Corcoran et al, 2012, 2015; Franks \& Lykke-Andersen, 2007; Blanco et al, 2014;

82 Vindry et al, 2017). Because ARE-mRNAs code for potent regulatory molecules such as

83 inflammatory cytokines, PBs are important post-transcriptional regulator that fine tune the

84 production of inflammatory cytokines whose transcripts contain AREs, including IL-6, IL-8, IL- 
1ß, and TNF (Ensoli et al, 2010; Ensoli \& Stürzl, 1998; Lane et al, 2002; Miles et al, 1990; Riva

et al, 2010; Sadagopan et al, 2007; Salahuddin et al, 1988; Bakheet et al, 2018).

87

PBs are dynamic structures that are continuously assembled and disassembled, yet relatively pathway as well as many virus infections elicit PB disassembly and a concomitant reduction in ARE-mRNA suppression to promote inflammatory molecule production (Corcoran et al, 2012, 2015; Vindry et al, 2017; Corcoran \& McCormick, 2015; Standart \& Weil, 2018; Docena et al, 2010). We have previously shown that KSHV causes PB disassembly during latent infection, and that the viral protein Kaposin B (KapB) induces PB disassembly while enhancing the production of an ARE-containing reporter (Corcoran et al, 2015; Corcoran \& McCormick, 2015; Corcoran et al, 2011). These data support the notion that PB disassembly is likely an important contributor

97 to inflammation associated with KS (Corcoran et al, 2015; Wen \& Damania, 2010). Although we know that KapB binds and activates the kinase MK2, and that MK2 is an important component of the mechanism of KapB-mediated PB disassembly and ARE-mRNA stabilization, we do not precisely understand how PB loss is elicited by KapB (McCormick \& Ganem, 2005; Corcoran et al, 2015). The observation that MK2 can phosphorylate Beclin-1 to increase autophagic flux in response to nutrient scarcity (Wei et al, 2015) suggested to us that KapB may also drive autophagic flux. We now show that the KSHV KapB protein enhances autophagic flux, revealing 104 an additional layer of complexity in viral regulation of autophagy during KSHV latency. We also show that KapB requires canonical autophagy machinery Atg5 and Atg14 to induce PB disassembly and ARE-mRNA stabilization and that KapB selects PB components for autophagic turnover using the selective autophagy receptor, NDP52. PB turnover is also elicited by the 
108 mTOR inhibitor and potent autophagy inducer, Torin-1, and this process is also dependent on 109 Atg5 and NDP52. In contrast, and despite previous observations that it elicits PB disassembly 110 and ARE-mRNA stabilization (Corcoran et al, 2015), a constitutively active form of MK2 does

111 not rely on canonical or selective autophagy machinery for PB loss. Our data reveal that cells

112 possess both autophagy-dependent and -independent mechanisms to regulate PB turnover and

113 inflammatory molecule production. These data also forge a new connection between the

114 selective autophagy receptor, NDP52, and cytoplasmic PBs, both of which control innate

115 immune responses and inflammation. 


\section{$117 \quad$ Results}

\section{KapB induces autophagic flux}

119 KapB expression activates the stress-responsive kinase MAPKAPK2 (MK2) (McCormick \&

120 Ganem, 2005; Corcoran et al, 2015). Since MK2 phosphorylates the essential autophagy inducer

121 Beclin 1 in response to amino acid starvation (Wei et al, 2015; Shen et al, 2016; Gurkar et al,

122 2013), we questioned whether KapB expression could promote autophagic flux. Essential for

123 autophagosome expansion is the lipidation of LC3 to form LC3-II, permitting its incorporation

124 into autophagosome membranes (Klionsky et al, 2012). To measure autophagic flux, we

125 examined levels of LC3-II and the SAR, p62, with and without treatment with the lysosomal inhibitor, Bafilomycin A1 (BafA1), as both LC3-II and p62 are also substrates for autophagy

127 (Mizushima et al, 2010; Mauvezin \& Neufeld, 2015). To this end, human umbilical vein endothelial cells (HUVECs) were transduced with lentiviral vectors that express KapB or an empty vector control and treated for increasing times with BafA1; LC3-II and p62 accumulation in the presence or absence of BafA1 treatment was determined by immunoblotting. When KapBexpressing cells were treated for $4 \mathrm{~h}$ with BafA1, the amount of LC3-II and p62 increased twoand four-fold, respectively, compared to untreated cells. Both proteins showed higher accumulation after BafA1 treatment of KapB-expressing cells than equivalently treated vector controls (Fig 1A), indicating that autophagic flux was specifically enhanced in KapB-expressing cells. We also measured endogenous LC3 puncta using immunofluorescence as an indicator of autophagic flux (Kabeya, 2000; Mizushima et al, 2010). Untreated KapB-expressing HUVECs

137 displayed LC3 puncta area similar to that of control cells; however, LC3 puncta area increased after BafA1 treatment, further suggesting that KapB expression enhanced autophagic flux (Fig 1B). Taken together, these data show that KapB expression induced autophagic flux in HUVECs. 


\section{Canonical autophagy is required for KapB- and Torin-mediated PB disassembly}

141 Our group previously described that MK2 activation was an important component of KapBmediated PB loss (Corcoran et al, 2015); however, these experiments did not reveal the precise mechanism of PB loss nor did they clarify if KapB was causing PB disassembly or blocking PB assembly. Since PBs are dynamic RNP granules, we wanted to determine whether KapBmediated PB loss was a result of enhanced disassembly of PBs or prevention of their de novo assembly. To do so, we utilized HeLa cells that express a Dox-inducible GFP-tagged version of the PB-resident protein, Dcpla (Youn et al, 2018). When fixed, GFP-positive puncta co-stain with endogenous PB proteins such as the RNA helicase DDX6/Rck and the decapping co-factor Hedls/Edc4, indicating that they represent PBs (Fig S1). KapB was transfected into these cells either before or after inducing GFP-Dcpla granule formation. When KapB was expressed prior to granule induction, Dcpla puncta formation was intact, although their appearance was slightly delayed compared to vector control cells (Fig S1A). However, when KapB was expressed after granule induction, GFP-positive puncta were lost (Fig S1B), indicating that KapB expression induced PB disassembly. As further evidence, we treated KapB-expressing HUVECs with sodium arsenite, a known inducer of PB assembly. We observed that sodium arsenite induced endogenous PB formation in KapB-expressing HUVECs that was indistinguishable from 157 equivalently treated control cells (Fig S1C). Taken together, these results show that KapB 158 expression caused PB loss by inducing PB disassembly but did not block PB assembly. We 159 speculated that KapB may be utilizing a normal cellular pathway that mediates the turnover of RNPs, such as autophagy. autophagic flux by independently silencing two canonical autophagy genes, Atg5 and Atg14 (Fig 
S2A, B). When either Atg5 or Atg14 were silenced in KapB-expressing HUVECs, PBs were restored, whereas their silencing did not have an effect in control cells (Fig 1C and D). We then examined the ability of KapB to mediate PB disassembly in Atg5 -/- MEFs, which are defective for autophagy (Katayama et al, 2008), as indicated by the lack of LC3-II (Fig S2C). KapB failed to disassemble PBs in Atg5 -/- MEFs but did disassemble PBs in matched wild-type controls (Fig S2D). Moreover, KapB expression resulted in a significant increase in Atg5 protein levels (Fig S2A), consistent with our other data that show that KapB is promoting autophagy. Blocking autophagic degradation with BafA1 also restored PBs in KapB-expressing cells (Fig 1E). These data suggest that KapB is accelerating PB turnover by enhancing autophagy.

Autophagy, although always occurring at a basal level, can be upregulated by many different cell stimuli including starvation or inhibition of mTOR using Torin-1, hereafter referred to as Torin (Thoreen et al, 2009). It was previously reported that rapamycin, an inhibitor of mTORC1, caused a loss of PBs in mammary epithelial cells (Hardy et al, 2017). We reasoned that if we inhibited both mTOR complexes mTORC1 and mTORC2 (Liu et al, 2013) using Torin, PBs would disassemble. We observed that the number of Hedls/Edc4 puncta were significantly reduced after Torin treatment, indicating that chemical induction of autophagy also resulted in the disassembly of PBs in HUVECs (Fig 2A). To ensure that Torin treatment was inducing disassembly of PBs and not preventing assembly, HUVECs were treated with sodium arsenite to induce PB formation; like KapB, Torin treatment did not prevent the assembly of PBs under stress conditions (Fig 2B). We then silenced Atg5 and tested if Torin treatment was able to disassemble PBs in these cells. Although Torin caused PB disassembly in control cells, Torin failed to alter the number of Hedls/Edc4 puncta in cells expressing shAtg5 (Fig 2C). Taken 
185 together, these data show that PB turnover requires autophagy in response to both KapB and 186 Torin.

187 Canonical autophagy is required for KapB-mediated increases in ARE-containing cytokine

PBs are nodes of mRNA regulation and microscopically visible PBs are associated with AREmRNA decay or suppression (Guo et al, 2018; Luo et al, 2018; Corcoran et al, 2015, 2012;

191 Franks \& Lykke-Andersen, 2008; Vindry et al, 2017; Blanco et al, 2014). We treated HUVECs

192 with conditioned media from latent KSHV-infected cells to stimulate the transcription of

193 inflammatory RNAs in a biologically relevant manner and examined levels of some endogenous

194 ARE-containing RNA transcripts in KapB-expressing cells (Fig 3A). We observed significant

195 increases of cytokine mRNA for IL-6 and IL- $1 \beta$ in KapB-expressing cells compared to

196 equivalently treated controls, suggesting these increases resulted from reduced transcript

197 turnover in PBs (Fig 3A). In addition, treatment with Torin promoted the enhanced steady-state

198 levels of IL-1 $\beta$ and COX-2 (Fig 3B), suggesting that inducing autophagy reduces turnover of

199 some ARE-mRNA transcripts. To support these findings and to simplify further studies, we

200 utilized a luciferase reporter assay that we previously developed, described in (Corcoran et al,

201 2011). We previously used this assay to show that KapB-mediated PB loss correlated with

202 enhanced luminescence of an ARE-containing firefly luciferase (Fluc) reporter because its rapid

203 turnover was reversed and FLuc translation was enhanced (Corcoran et al, 2011, 2015). Briefly,

204 HeLa cells were co-transfected with a FLuc construct containing the AU-rich element from

205 CSF2 in its 3'UTR and a Renilla luciferase (RLuc) construct with no ARE; transcription of both

206 reporter constructs was then stopped by the addition of doxycycline. In control (vector

207 transfected) cells, the FLuc-ARE mRNA decayed rapidly and FLuc luminescence relative to the 
208 RLuc transfection control was low. Torin treatment caused a significant increase in FLuc/RLuc

209 relative luminescence compared to DMSO-treated control cells, supporting our RT-qPCR

210 findings (Fig 3C) and suggesting that enhanced autophagy reverses the constitutive

211 turnover/suppression of the ARE-mRNA reporter. Furthermore, KapB expression also caused a

212 significant increase in FLuc/RLuc relative luminescence compared to empty vector control cells

213 (Fig 3D) as previously shown in (Corcoran et al, 2015). When canonical autophagy was

214 perturbed by either Atg5 or Atg14 silencing (Fig S3A, B) KapB-expressing cells had

215 significantly decreased luminescence compared to KapB-expressing controls (Fig 3D, E).

216 Likewise, when KapB-expressing cells were treated with BafA1, relative luminescence was

217 significantly decreased compared to KapB-expressing untreated control cells (Fig 3F). Together,

218 these data showed that canonical autophagy is required for KapB-mediated increases in cytokine

219 mRNA levels and the enhanced expression of an ARE-mRNA reporter.

\section{Dcp1a protein levels are decreased by KapB and Torin treatment}

222 We reasoned that if KapB and Torin required autophagy for PB turnover, KapB expression or

223 Torin treatment may decrease steady-state levels of one or more key PB proteins that have

224 important scaffolding roles for granule formation, such as EDC4/Hedls, Xrn1, DDX6/Rck, or

225 Dcpla (Ayache et al, 2015). Immunoblotting for these proteins revealed that steady-state levels

226 of the PB-resident protein Dcpla were reduced in Torin-treated (Fig 4A) and KapB-expressing

227 cells (Fig 4B); however, steady-state levels of other PB-resident proteins were not affected (Fig

2284 A, C). These data suggest that autophagy induction with Torin or KapB expression promote the

229 turnover of the PB-resident protein Dcp1a, but not all PB proteins. Silencing the canonical 
autophagy gene, Atg5, resulted in a reversal of KapB-mediated Dcp1a loss (Fig 4D), suggesting that autophagy is required for the loss of Dcpla observed after KapB expression.

\section{KapB-mediated PB disassembly and ARE-mRNA stabilization require the selective autophagy receptor NDP52}

After establishing a link between KapB expression, autophagy, and PB disassembly, we wondered what specific autophagy mechanisms were at work and if selective autophagy receptors (SARs) were involved. Very little is known about how PB dynamics are regulated; however, one previous study observed the SAR, NDP52, partially co-localized with some PB proteins (Guo et al, 2014). For this reason, we investigated whether NDP52, p62, VCP, NBR1, or OPTN were required for KapB-mediated PB disassembly using RNA silencing. Despite trying several different shRNA sequences, our attempts to silence NBR1 were unsuccessful, and shRNAs targeting VCP resulted in significant HUVEC toxicity (Fig S4A, B). Therefore, the role of these molecules in PB turnover could not be determined in our model. Genetic knockdown of NDP52, p62, and OPTN was validated in control and KapB-expressing cells (Fig S4C-E). In these experiments, silencing of p62 or OPTN did not restore PBs in KapB-expressing cells whereas NDP52 knockdown significantly restored PBs (Fig 5A, Fig S4F). These data pinpointed an important role for NDP52 and selective autophagy in KapB-mediated PB disassembly. We then tested whether NDP52 silencing could prevent Torin-mediated PB disassembly and found that PBs could not be disassembled in cells lacking NDP52 (Fig 5B, S4G). We also examined whether these SARs were required for KapB-enhanced relative luminescence in our AREmRNA reporter assay. We validated silencing of NDP52, p62, and OPTN in HeLas (Fig S5A-C). Similarly, we found that p62 or OPTN knockdown had no effect on KapB-mediated FLuc/RLuc 
253 luminescence, but NDP52 silencing decreased FLuc/RLuc luminescence compared to non-

254 targeting, KapB-expressing controls (Fig 5C), further supporting the role of NDP52 in

255 autophagy-mediated PB disassembly. Therefore, KapB-stimulated PB disassembly and

256 concomitant luminescence of our ARE-containing reporter uses a mechanism dependent on

257 NDP52.

NDP52 requires the ubiquitin-binding domain for KapB-mediated PB disassembly

259 NDP52 has many functions in selective autophagy and autophagosome maturation and is a crucial adaptor for mitophagy and xenophagy (Ellinghaus et al, 2013; Fu et al, 2018; Lazarou et al, 2015; Morriswood et al, 2007; Verlhac et al, 2015). Structural domains that are important for 262 the function of NDP52 as a SAR include a non-canonical LC3-C interacting region (cLIR) that binds to LC3-decorated autophagosomes and a ubiquitin binding domain (UBD) that binds ubiquitinated cargo proteins, linking them to the autophagosome for engulfment (Fig 5D) To elucidate if NDP52 was required for KapB-mediated PB disassembly because of its ability to

266 promote selective autophagy, we performed a complementation experiment. We first silenced

267 endogenous NDP52 in control or KapB-expressing HUVECs using shRNAs targeting the 3'UTR

268 of NDP52 and verified its knockdown (Fig S6A). Next, NDP52 expression was restored by

269 overexpressing a fluorescently tagged NDP52 construct. Complementation of NDP52-silenced HUVECs with wild-type NDP52 restored KapB-mediated PB disassembly compared to vector

271 controls (Fig 5E, F; S6B, C). We next sought to determine whether the PB disassembly initiated

272 in KapB-expressing cells was reliant on two domains of NDP52 that are important for its role as

273 a SAR: the LIR and UBD. We restored NDP52 expression in NDP52-silenced HUVECs by

274 complementation with a fluorescently tagged UBD mutant (C443K) or a cLIR and UBD

275 combined mutant (V136S and C443K) (Padman et al, 2019; Ellinghaus et al, 2013; Till et al, 
2013) (Fig 5E, F). Complementation with either of the mutated forms of NDP52 failed to restore KapB-mediated PB disassembly in NDP52-silenced HUVECs. These data indicated that the UBD of NDP52 is required for KapB-mediated PB disassembly and suggest that the LIR domain may also be important (Fig 5E, F). These data provide evidence to support that the function of NDP52 in selective autophagy is required for its role in KapB-mediated PB disassembly.

\section{Canonical autophagy is not required for MK2-mediated PB disassembly}

Because we know that KapB can directly bind and activate MK2 (McCormick \& Ganem, 2005) and that MK2 is, in part, required for KapB-mediated effects on PBs and ARE-mRNA (Corcoran et al, 2015), we reasoned that a constitutively active version of MK2 would also induce PB disassembly in an autophagy-dependent manner. To test this, we used a phosphomimetic construct called MK2EE in which two threonine residues that are normally phosphorylated by p38 MAPK in response to stress signaling are substituted with glutamic acid residues, rendering the kinase constitutively active (Kayyali et al, 2002; Rousseau et al, 1997). We previously demonstrated that MK2EE causes PB disassembly (Corcoran et al, 2015) and others have shown that it can also increase autophagic flux (Wei et al, 2015). We confirmed that autophagy was upregulated in MK2EE-expressing HUVECs by staining for endogenous LC3 puncta. We observed that BafA1 treatment resulted in a significant increase in LC3-puncta compared to vector controls, consistent with enhanced autophagic flux (Fig 6A). Furthermore, MK2EE expression resulted in an increased accumulation of LC3-II and p62 after Baf A1 treatment to block degradation (Fig 6B). We then tested if MK2EE-induced PB disassembly was reliant on autophagic flux. MK2EE-expressing HUVECs retained the ability to disassemble PBs after Atg5 silencing (Fig 6C, S7A). MK2EE expression was previously shown to increase the FLuc/RLuc 
299 relative luminescence in our reporter assay (Corcoran et al, 2015) and we reproduced these data

300 herein (Fig 6D). However, Atg5 silencing did not significantly decrease MK2EE-mediated

301 relative luminescence (Fig 6D, S7B). These data suggest that although MK2EE induces

302 autophagy and PB disassembly, these are unrelated phenotypes and the manner by which

303 MK2EE induces PB loss does not require canonical autophagy pathways involving Atg5.

304 Given that MK2 induces autophagy, but MK2EE-mediated PB disassembly did not require

305 canonical autophagy machinery, we speculated that MK2EE-mediated PB disassembly could be

306 facilitated by NDP52. However, p62, NDP52 and OPTN silencing did not inhibit PB

307 disassembly in MK2EE-expressing cells (Fig S7C-E; 6E; S7F). Likewise, silencing of p62,

308 OPTN, or NDP52 did not decrease FLuc/RLuc luminescence in MK2EE-expressing cells as it

309 did in KapB-expressing cells (Fig 6F, S7G-I). In fact, NDP52 knockdown increased ARE-

310 mRNA stability (Fig 6F), although the significance of this observation is unclear. These data

311 confirm that MK2-mediated PB disassembly and enhanced ARE-containing luciferase reporter

312 expression do not require canonical autophagy or selective autophagy machinery. 


\section{$\underline{\text { Discussion }}$}

Here we demonstrate that the KSHV protein, KapB, relies on selective autophagy to cause PB disassembly and enhance ARE-mRNA stability. We furthermore identified NDP52 as the selective autophagy receptor required for this process. To our knowledge, this is the first report that NDP52 regulates the turnover of endogenous PBs and the first description of the contribution of NDP52 to immune regulation by altering inflammatory cytokine RNA turnover/suppression in PBs. Our major findings are: i) KapB increases autophagic flux, thereby contributing to the complex regulation of autophagic processes during KSHV latent infection and tumourigenesis, ii) KapB-mediated PB disassembly and enhanced translation of an AREcontaining reporter requires canonical autophagy machinery and the selective autophagy receptor, NDP52, iii) Activation of autophagy by chemical inhibition of mTORC1 using Torin causes PB disassembly using a mechanism that is dependent on canonical autophagy and NDP52, suggesting that KapB manipulates an existing cellular pathway that regulates PB catabolism, and iv) the mechanism of KapB- or Torin-mediated PB disassembly differs from that induced by the constitutively active kinase, MK2 (MK2EE), which is autophagy- and NDP52independent. These results reveal that PB turnover is mediated by autophagy-dependent and independent mechanisms and shows that the viral KapB protein hijacks a host pathway that uses NDP52 to enhance PB catabolism and promote inflammatory molecule production.

MK2 activation promotes autophagy by phosphorylating Beclin 1 (Wei et al, 2015); therefore, we hypothesized that KapB, an MK2-activating viral protein (McCormick \& Ganem, 2005), would utilize autophagy to promote PB clearance. Our data showed that although both KapB and MK2EE increased autophagic flux (Fig 1, Fig 6), only KapB-mediated PB disassembly required 
the canonical autophagy proteins Atg5 and Atg14, and the selective autophagy protein NDP52 (Fig 1, Fig 5). MK2EE does not use an autophagy-dependent mechanism, as KapB does, for PB disassembly and our studies have not yet revealed a mechanism for PB loss in these cells. These data imply that cells employ more than one pathway to disassemble PBs, consistent with the dual mechanisms responsible for turnover of other RNP granules like stress granules (Buchan et al, 2013; Turakhiya et al, 2018). Our data also suggest that KapB hijacks both these pathways to utilize an MK2-dependent, autophagy-independent pathway and an NDP52-, autophagydependent pathway to disassemble PBs, suggesting the central importance of PB loss to KSHV latency. Our data are supported by previous work showing that in yeast, PB recycling requires canonical autophagy machinery, and in mammalian cells NDP52 colocalizes with a GFP-tagged version of Dcpla when overexpressed (Buchan et al, 2013; Guo et al, 2014). We add significantly to these studies, by performing our work in primary human endothelial cells and by staining for endogenous PBs using immunofluorescence for the decapping co-factor Hedls/EDC4. We reveal that when KapB is expressed, endogenous PBs are disassembled by an Atg5-, Atg14-, and NDP52-dependent autophagy process. We also complemented NDP52silenced cells with an shRNA-resistant NDP52. We observed the restoration of KapB-mediated PB disassembly when complementation was performed with wild-type NDP52 but not when lacking the UBD (Fig 5). These data suggest that it is the ability of NDP52 to bind ubiquitinated cargo for autophagic degradation that is required for KapB-mediated PB turnover, as has been observed in other studies on NDP52 SAR function (Xie et al, 2015; Cemma et al, 2011).

Immunoelectron microscopy showed that PBs range in size from 150 to $350 \mathrm{~nm}$ and possess an external area of peripheral protrusions that contain the helicase Rck/DDX6 anchored to a dense 
central core of decay enzymes, including Dcp1a and Xrn1 (Cougot et al, 2012). Many PBlocalized enzymes are required for PB stability including Dcp1a; however, only three PB proteins are required for de novo $\mathrm{PB}$ formation, DDX6, the translation suppressor, 4E-T, and LSM14a (Ayache et al, 2015). Our data showed that KapB expression decreased the steady-state levels of Dcp1a, while the steady-state levels of other PB proteins were unaffected (Fig 4). Inducing autophagy with the mTORC1/2 inhibitor Torin recapitulated this effect, decreasing steady-state levels of Dcpla, but not other PB proteins (Fig 4). These data support a model where the entire PB granule is not degraded by autophagy, but PB disassembly is induced by the selective targeting of Dcpla or another unidentified PB protein. Consistent with this, we show that PBs can still form during KapB expression if we overexpress Dcpla-GFP or block translation using sodium arsenite (Fig S1). Dcpla is also a target for other viruses that mediate PB disassembly; for example, infection with poliovirus also caused PB disassembly and the loss of Dcpla over a time course of infection (Dougherty et al, 2011).

We do not yet understand how KapB expression or Torin treatment alters Depla to promote its degradation, but we speculate that post-translational modification of Dcpla is involved. PB proteins, including Dcp1a, EDC4/Hedls, Dcp2 and DDX6, are phosphorylated; however, the functional consequences of these phosphorylation events for PB granule formation are not yet fully appreciated (Bish et al, 2015; Gustafson \& Wessel, 2010; Rahman et al, 2014; Yoon et al, 2010). Dcp1a is mono-phosphorylated at serine 315 which stabilizes its interaction with Dcp2; however, hyperphosphorylation of Dcpla coincided with PB loss, showing that Dcpla phosphorylation status regulates PB dynamics (Tenekeci et al, 2016; Aizer et al, 2013; Chiang et al, 2013). PB proteins including Dcp1a, Dcp2 and EDC3 are also ubiquitinated, and 
manipulation of total cellular K63-ubiquitination altered PB formation and function and changed the mRNA half-life of selected cytokine transcripts in a gene-specific manner (Tenekeci et al,

386 2016). Our model is that KapB expression induces the post-translational modification of Dcp1a, or a yet to be identified PB protein, to increase its recognition by NDP52, which then targets it to nascent autophagosomes (model Fig 7). Future work will explore the interactome of NDP52

389 during KapB expression to determine Dcpla post-translational modifications and whether other 390 PB proteins are modified or targeted for degradation.

392 In viral cancers like KS, autophagic flux promotes a pro-tumourigenic and pro-inflammatory 393 environment (Vescovo et al, 2020; Liu \& Debnath, 2016; Pringle et al, 2019; Wu et al, 2012).

394 The data shown herein brings new understanding to this complex relationship during KSHV 395 infection. We show that KapB induces autophagic flux and NDP52 selective autophagy of PBs, 396 thereby supporting the pro-inflammatory environment associated with latent KSHV infection and 397 KS. The manipulation of NDP52 function and autophagic flux by KapB is yet another example 398 of the ingenuity with which viruses usurp cellular processes; revealing a regulatory network that 399 links NDP52 to inflammatory molecule production via PB catabolism. 
Materials and Methods

402

\section{Cell culture}

403 All cells were grown at $37{ }^{\circ} \mathrm{C}$ with $5 \% \mathrm{CO}_{2}$ and $20 \% \mathrm{O}_{2}$. HEK293T cells (ATCC), HeLa Tet-Off

404 cells (Clontech), Atg5 +/+ and -/- MEFs (Kuma et al, 2004), HeLa Flp-In TREx GFP-Dcpla

405 cells (a generous gift from Anne-Claude Gingras)(Youn et al, 2018), and iSLK.219 cells (a

406 generous gift from Don Ganem) (Myoung \& Ganem, 2011) were cultured in DMEM (Thermo

407 Fisher) supplemented with $100 \mathrm{U} / \mathrm{mL}$ penicillin, $100 \mu \mathrm{g} / \mathrm{mL}$ streptomycin, $2 \mathrm{mM}$ L-glutamine

408 (Thermo Fisher) and 10\% FBS (Thermo Fisher). iSLK.219 cells were additionally cultured in the

409 presence of puromycin $(10 \mu \mathrm{g} / \mathrm{mL})$. HUVECs (Lonza) were cultured in endothelial cell growth

410 medium (EGM-2) (Lonza). HUVECs were seeded onto gelatin (1\% w/v in PBS)-coated tissue

411 culture plates or glass coverslips. All drug treatments were performed for the times indicated in

412 each experiment at the concentrations listed in Table 1.

\section{$413 \quad$ Cloning}

414 All plasmids used in this study can be found in Table 2. All shRNAs were generated by cloning

415 shRNA hairpin sequences found in Table 3 into pLKO.1-TRC Puro (pLKO.1-TRC cloning

416 vector was a gift from David Root (Addgene plasmid \# 10878; http://n2t.net/addgene:10878;

417 RRID:Addgene_10878) or pLKO.1-blast (pLKO.1-blast was a gift from Keith Mostov (Addgene 418 plasmid \#26655; http://n2t.net/addgene:26655; RRID:Addgene_26655). pBMN mCherry-

419 NDP52(C443K) was a gift from Michael Lazarou (Addgene plasmid \#119685;

420 http://n2t.net/addgene:119685; RRID:Addgene_119685) and pBMN mCherry-

421 NDP52(V136S/C443K) was a gift from Michael Lazarou (Addgene plasmid \#119686;

422 http://n2t.net/addgene:119686; RRID:Addgene_119686). The overexpression plasmids, pLJM1 
423 mCh-NDP52 C443K and pLJM1 mCh-NDP52 C443K V136S were made using the primers in

424 Table 4 to clone NDP52 into pLJM1 (Johnston et al, 2019).

$425 \quad$ Lentivirus Production and Transduction

426 All lentiviruses were generated using a second-generation system. Briefly, HEK293T cells were

427 transfected with pSPAX2, MD2G, and the plasmid containing a gene of interest or hairpin using

428 polyethylimine (PEI, Polysciences). psPAX2 was a gift from Didier Trono (Addgene plasmid

$429 \quad \# 12260 ;$ http://n2t.net/addgene:12260; RRID:Addgene_12260) and pMD2.G was a gift from

430 Didier Trono (Addgene plasmid \#12259; http://n2t.net/addgene:12259; RRID:Addgene_12259).

431 Viral supernatants were harvested $48 \mathrm{~h}$ post-transfection, clarified using a $0.45 \mu \mathrm{m}$

432 polyethersulfone filter (VWR), and frozen at $-80^{\circ} \mathrm{C}$ until use. For transduction, lentiviruses were

433 thawed at $37^{\circ} \mathrm{C}$ and added to target cells in complete media containing $5 \mu \mathrm{g} / \mathrm{mL}$ polybrene

434 (Sigma) for $24 \mathrm{~h}$. The media was changed to selection media containing $1 \mu \mathrm{g} / \mathrm{mL}$ puromycin or 5

$435 \mu \mathrm{g} / \mathrm{mL}$ blasticidin (Thermo) and cells were selected for $48 \mathrm{~h}$ before proceeding with

436 experiments.

$437 \quad$ Viral conditioned media treatment

438 iSLK.219 cells (latently infected with rKSHV.219 virus) (Vieira \& O'Hearn, 2004) were sub-

439 cultured into a $10 \mathrm{~mL}$ cell culture dish and grown without puromycin for $72 \mathrm{~h}$ (Myoung \&

440 Ganem, 2011). At 72 h, conditioned media was reserved and cleared of cellular debris by

441 centrifugation at $500 \mathrm{x}$ g for $5 \mathrm{~min}$. Supernatant was collected and filtered through a $0.22 \mu \mathrm{m}$

442 polyethersulfone (PES) membrane filter (VWR) and stored in aliquots at -80 . Prior to the

443 experiment, conditioned media was thawed at $37^{\circ} \mathrm{C}$ and combined $1: 1$ with fresh HUVEC EGM- 
4442 media and used to treat vector or KapB-expressing HUVECs for 0 or $6 \mathrm{~h}$ prior to total RNA

445 harvest.

446 Immunofluorescence

447 Cells were seeded onto coverslips for immunofluorescence experiments and fixed for 10 mins at

$448 \quad 37^{\circ} \mathrm{C}$ in $4 \%(v / v)$ paraformaldehyde (Electron Microscopy Sciences). Samples were

449 permeabilized with $0.1 \%(\mathrm{v} / \mathrm{v})$ Triton X-100 (Sigma-Aldrich) for $10 \mathrm{~min}$ at room temperature

450 and blocked in 1\% human AB serum (Sigma-Aldrich) for $1 \mathrm{~h}$ at room temperature. For

451 autophagosome immunofluorescence cells were fixed for $10 \mathrm{~min}$ in ice cold methanol at $-20{ }^{\circ} \mathrm{C}$

452 and blocked in $1 \%$ human $\mathrm{AB}$ serum for $1 \mathrm{~h}$ at room temperature. Primary and secondary

453 antibodies were diluted in 1\% human $\mathrm{AB}$ serum and used at the concentrations in Table 5.

454 Samples were mounted with Prolong Gold AntiFade mounting media (Thermo). For CellProfiler

455 quantification of puncta, samples were incubated with WGA AlexaFluor-647 at a 1:400 dilution

456 for 10 min prior to permeabilization. Image analysis was performed using CellProfiler

457 (cellprofiler.org), an open source platform for image analysis (Carpenter et al, 2006);

458 quantification of puncta was performed as previously described, with the exception that cells

459 were defined by propagating out a set number of pixels from each nucleus (Castle et al, 2021).

\section{Immunoblotting}

461 Cells were lysed in $2 \mathrm{x}$ Laemmli buffer and stored at $-20^{\circ} \mathrm{C}$ until use. The DC Protein Assay

462 (Bio-Rad) was used to quantify protein concentration as per the manufacturer's instructions. 10-

$46315 \mu \mathrm{g}$ of protein lysate was resolved by SDS-PAGE on TGX Stain-Free acrylamide gels

464 (BioRad). Total protein images were acquired from the PVDF membranes after transfer on the

465 ChemiDoc Touch Imaging system (BioRad). Membranes were blocked in 5\% bovine serum 
466 albumin (BSA) or skim milk in Tris-buffered saline-Tween20 (TBS-T). Primary and secondary

467 antibodies were diluted in $2.5 \%$ BSA or skim milk; antibody dilutions can be found in Table 5.

468 Membranes were visualized using Clarity Western ECL substrate and the ChemiDoc Touch

469 Imaging system (BioRad).

$470 \quad$ Luciferase Assays

471 Luciferase assays were performed as previously described (Corcoran et al, 2011). HeLa Tet-Off

472 cells were transduced with recombinant lentivirus expressing different shRNAs and selected.

473 Cells were transfected according to Corcoran et al. (2011) with pTRE2 Firefly Luciferase ARE,

474 pTRE2 Renilla Luciferase, and the expression plasmid of interest using Fugene HD (Promega).

475 Luciferase and renilla activity were quantified using the Dual Luciferase Assay Kit (Promega)

476 and read on a GloMax multi-detection system (Promega).

\section{Quantitative PCR}

478 RNA was collected using a RNeasy Plus Mini Kit (Qiagen) according to the manufacturer's

479 instructions and stored at $-80^{\circ} \mathrm{C}$ until further use. RNA concentration was determined and was

480 reverse transcribed using Maxima H Minus First Strand cDNA Synthesis Kit (Thermo Fisher)

481 using a combination of random and oligo (dT) primers according to the manufacturer's

482 instructions. cDNA was diluted 1:5 for all qPCR experiments and GoTaq qPCR Master Mix

483 (Promega) was used to amplify cDNA. The $\Delta \Delta$-Quantitation cycle $(\mathrm{Cq})$ method was used to

484 determine the fold change in expression of target transcripts. qPCR primer sequences can be

485 found in Table 6.

$486 \quad \underline{\text { Statistics }}$ 
bioRxiv preprint doi: https://doi.org/10.1101/2021.02.07 430164; this version posted June 21, 2021. The copyright holder for this preprint (which was not certified by peer review) is the author/funder, who has granted bioRxiv a license to display the preprint in perpetuity. It is made available under aCC-BY 4.0 International license.

487 Data shown are the mean \pm standard error of the mean (SEM). Statistical significance was

488 determined using a one-way ANOVA, a 2-way ANOVA or Student's t-test when appropriate

489 with the applicable post-test (indicated in the corresponding figure legends). For ANOVAs,

490 matched data from each replicate was paired for analysis. All statistics were performed using

491 GraphPad Prism v.9.0.

492

493 


\section{Acknowledgements}

495 The authors would like to dedicate this manuscript to Dr. Beth Levine, who was a leader in the

496 field of autophagy and viruses and who inspired this work. We sincerely thank the members of

497 the Corcoran lab for helpful discussions about this work. We would like to thank Dr. Craig

498 McCormick (Dalhousie University), Dr. Eric Pringle (Dalhousie University), and Dr. Andrew

499 Leidal (UCSF) for valuable feedback on this manuscript and the McCormick lab for plasmids,

500 expertise and advice. We would like to thank Mr. Stephen Whitefield and Ms. Mary Ann Trevors

501 in the Dalhousie CORES (Cellular and Molecular Digital Imaging and Electron Microscopy core

502 facilities) and Dr. Anne Vaahtokari of the Charbonneau Microscopy Facility, UCalgary for

503 microscopy support. We would like to thank Dr. Andreas Till (University of Bonn), Dr. Anne-

504 Claude Gingras (Lunenfeld-Tanenbaum Research Institute) and Dr. Don Ganem (Novartis) for

505 sharing valuable reagents. Model figure created with BioRender. GKS was supported by a CIHR

506 CGS-M scholarship and Scotia Scholars NSHRF graduate training award. ELC was supported by

507 a Killam predoctoral scholarship, an NSERC CGS-M scholarship, and a Nova Scotia Graduate

508 scholarship. Operating funds to support this work derive from a CIHR Project Grant PJT-153210

509 to JAC.

510

511 Author Contributions

512 Carolyn-Ann Robinson: Conceptualization, Experimentation, Analysis, Paper Writing

513 Gillian K. Singh: Conceptualization, Experimentation, Analysis, Paper Writing

514 Elizabeth L. Castle: Analysis 
bioRxiv preprint doi: https://doi.org/10.1101/2021.02.07 430164; this version posted June 21, 2021. The copyright holder for this preprint (which was not certified by peer review) is the author/funder, who has granted bioRxiv a license to display the preprint in perpetuity. It is made available under aCC-BY 4.0 International license.

515 Bre Q. Boudreau: Experimentation

516 Jennifer A. Corcoran: Conceptualization, Experimentation, Supervision, Funding Acquisition,

517 Project Administration, Paper Writing

519 Conflict of Interest

520 The authors have no competing interests to declare.

521

522 


\section{$\underline{\text { References }}$}

Ahmad L, Mostowy S \& Sancho-Shimizu V (2018) Autophagy-virus interplay: From cell biology to human disease. Front Cell Dev Biol 6 doi:10.3389/fcell.2018.00155 [PREPRINT]

528

529

530

531

532

533

534

535

536

537

538

539

540

541

542

543

544

545

546

547

548

549

550

551

552

553

554

555

556

557

558

559

560

Aizer A, Kafri P, Kalo A \& Shav-Tal Y (2013) The P Body Protein Dcp1a Is Hyperphosphorylated during Mitosis. PLoS One 8: e49783

Ayache J, Bénard M, Ernoult-Lange M, Minshall N, Standart N, Kress M \& Weil D (2015) Pbody assembly requires DDX6 repression complexes rather than decay or Ataxin $2 / 2 \mathrm{~L}$ complexes. Mol Biol Cell 26: 2579-2595

Bakheet T, Hitti E \& Khabar KSA (2018) ARED-Plus: An updated and expanded database of AU-rich element-containing mRNAs and pre-mRNAs. Nucleic Acids Res 46: D218-D220

Balgi AD, Fonseca BD, Donohue E, Tsang TCF, Lajoie P, Proud CG, Nabi IR \& Roberge M (2009) Screen for chemical modulators of autophagy reveals novel therapeutic inhibitors of mTORC1 signaling. PLoS One 4

Barreau C, Paillard L \& Osborne HB (2005) AU-rich elements and associated factors: Are there unifying principles? Nucleic Acids Res 33: 7138-7150 doi:10.1093/nar/gki1012 [PREPRINT]

Birgisdottir ÅB, Lamark T \& Johansen T (2013) The LIR motif - crucial for selective autophagy. J Cell Sci 126: 3237-47

Bish R, Cuevas-Polo N, Cheng Z, Hambardzumyan D, Munschauer M, Landthaler M \& Vogel C (2015) Comprehensive Protein Interactome Analysis of a Key RNA Helicase: Detection of Novel Stress Granule Proteins. Biomolecules 5: 1441-66

Blanco FF, Sanduja S, Deane NG, Blackshear PJ \& Dixon D a (2014) Transforming growth factor $\beta$ regulates $\mathrm{P}$-body formation through induction of the mRNA decay factor tristetraprolin. Mol Cell Biol 34: 180-95

Broussard G \& Damania B (2020) Regulation of KSHV Latency and Lytic Reactivation. Viruses 12 doi:10.3390/v12091034 [PREPRINT]

Buchan JR, Kolaitis R, Taylor JP \& Parker R (2013) Eukaryotic Stress Granules Are Cleared by Autophagy and Cdc48 / VCP Function. Cell 153: 1461-1474

Carpenter AE, Jones TR, Lamprecht MR, Clarke C, Kang I, Friman O, Guertin DA, Chang J, Lindquist RA, Moffat J, et al (2006) CellProfiler: image analysis software for identifying and quantifying cell phenotypes. Genome Biol 7: R100

Castle EL, Robinson C-A, Douglas P, Rinker KD \& Corcoran JA (2021) Viral manipulation of a mechanoresponsive signaling axis disassembles processing bodies. bioRxiv: 2020.05.15.091876

Cemma M, Kim PK \& Brumell JH (2011) The ubiquitin-binding adaptor proteins p62/SQSTM1 and NDP52 are recruited independently to bacteria-associated microdomains to target 
Salmonella to the autophagy pathway. Autophagy 7: 341-5

Cesarman E, Chang Y, Moore PS, Said JW \& Knowles DM (1995) Kaposi's sarcoma-associated herpesvirus-like DNA sequences in AIDS-related body-cavity-based lymphomas. $N$ Engl J Med 332: 1186-1191

Chang Y, Cesarman E, Pessin MS, Lee F, Culpepper J, Knowles DM \& Moore PS (1994) Identification of herpesvirus-like DNA sequences in AIDS-associated Kaposi's sarcoma. Science 266: 1865-9

Chen M, Meng Q, Qin Y, Liang P, Tan P, He L, Zhou Y, Chen Y, Huang J, Wang RF, et al (2016) TRIM14 Inhibits cGAS Degradation Mediated by Selective Autophagy Receptor p62 to Promote Innate Immune Responses. Mol Cell 64: 105-119

Chiang PY, Shen YF, Su YL, Kao CH, Lin NY, Hsu PH, Tsai MD, Wang SC, Chang GD, Lee SC, et al (2013) Phosphorylation of mRNA Decapping Protein Dcpla by the ERK Signaling Pathway during Early Differentiation of 3T3-L1 Preadipocytes. PLoS One 8

Corbet GA \& Parker R (2019) RNP granule formation: Lessons from P-bodies and stress granules. Cold Spring Harb Symp Quant Biol 84: 203-215

Corcoran JA, Johnston BP \& McCormick C (2015) Viral activation of MK2-hsp27p115RhoGEF-RhoA signaling axis causes cytoskeletal rearrangements, p-body disruption and ARE-mRNA stabilization. PLoS Pathog 11: e1004597

Corcoran JA, Khaperskyy DA, Johnston BP, King CA, Cyr DP, Olsthoorn A V. \& McCormick C (2012) Kaposi's Sarcoma-Associated Herpesvirus G-Protein-Coupled Receptor Prevents AU-Rich-Element-Mediated mRNA Decay. J Virol 86: 8859-8871

Corcoran JA, Khaperskyy DA \& McCormick C (2011) Assays for monitoring viral manipulation of host ARE-mRNA turnover. Methods 55: 172-181

Corcoran JA \& McCormick C (2015) Viral activation of stress-regulated Rho-GTPase signaling pathway disrupts sites of mRNA degradation to influence cellular gene expression. Small GTPases 6: 178-185 doi:10.1080/21541248.2015.1093068 [PREPRINT]

Cougot N, Cavalier A, Thomas D \& Gillet R (2012) The Dual Organization of P-bodies Revealed by Immunoelectron Microscopy and Electron Tomography. J Mol Biol 420: 1728

Decker LL, Shankar P, Khan G, Freeman RB, Dezube BJ, Lieberman J \& Thorley-Lawson DA (1996) The Kaposi sarcoma-associated herpesvirus (KSHV) is present as an intact latent genome in KS tissue but replicates in the peripheral blood mononuclear cells of KS patients. $J \operatorname{Exp}$ Med 184: 283-8

Docena G, Rovedatti L, Kruidenier L, Fanning Á, Leakey NAB, Knowles CH, Lee K, Shanahan F, Nally K, McLean PG, et al (2010) Down-regulation of p38 mitogen-activated protein kinase activation and proinflammatory cytokine production by mitogen-activated protein kinase inhibitors in inflammatory bowel disease. Clin Exp Immunol 162: 108-115

Dougherty JD, White JP \& Lloyd RE (2011) Poliovirus-mediated disruption of cytoplasmic processing bodies. J Virol 85: 64-75 
Du Y, Duan T, Feng Y, Liu Q, Lin M, Cui J \& Wang R (2018) LRRC25 inhibits type I IFN signaling by targeting ISG15-associated RIG-I for autophagic degradation. EMBO J 37: $351-366$

Dunn WA, Cregg JM, Kiel JAKW, van der Klei IJ, Oku M, Sakai Y, Sibirny AA, Stasyk O V. \& Veenhuis M (2005) Pexophagy: the selective autophagy of peroxisomes. Autophagy 1: 7583 doi:10.4161/auto.1.2.1737 [PREPRINT]

Ellinghaus D, Zhang H, Zeissig S, Lipinski S, Till A, Jiang T, Stade B, Bromberg Y, Ellinghaus E, Keller A, et al (2013) Association between variants of PRDM1 and NDP52 and Crohn's disease, based on exome sequencing and functional studies. Gastroenterology 145: 339-47

Ensoli B, Nakamura S, Salahuddin SZ, Biberfeld P, Larsson L, Beaver B, Wong-staal F \& Gallo RC (2010) AIDS-Kaposi's Sarcoma-Derived Cells Express Cytokines with Autocrine and Paracrine Growth Effects. Science (80- ) 243: 223-226

Ensoli B \& Stürzl M (1998) Kaposi's sarcoma: a result of the interplay among inflammatory cytokines, angiogenic factors and viral agents. Cytokine Growth Factor Rev 9: 63-83

Franks TM \& Lykke-Andersen J (2007) TTP and BRF proteins nucleate processing body formation to silence mRNAs with AU-rich elements. Genes Dev 21: 719-735

Franks TM \& Lykke-Andersen J (2008) The control of mRNA decapping and P-body formation. Mol Cell 32: 605-15

Fu T, Liu J, Wang Y, Xie X, Hu S \& Pan L (2018) Mechanistic insights into the interactions of NAP1 with the SKICH domains of NDP52 and TAX1BP1. Proc Natl Acad Sci U S A 115: E11651-E11660

García-Mauriño SM, Rivero-Rodríguez F, Velázquez-Cruz A, Hernández-Vellisca M, DíazQuintana A, De la Rosa MA \& Díaz-Moreno I (2017) RNA binding protein regulation and cross-talk in the control of AU-rich mRNA Fate. Front Mol Biosci 4: 71 doi:10.3389/fmolb.2017.00071 [PREPRINT]

Green DR, Galluzzi L \& Kroemer G (2011) Mitochondria and the autophagy-inflammation-cell death axis in organismal aging. Science (80- ) 333: 1109-1112 doi:10.1126/science.1201940 [PREPRINT]

Guo H, Chitiprolu M, Gagnon D, Meng L, Perez-Iratxeta C, Lagace D \& Gibbings D (2014) Autophagy supports genomic stability by degrading retrotransposon RNA. Nat Commun 5: 5276

Guo L, Louis IV-S \& Bohjanen PR (2018) Post-transcriptional regulation of cytokine expression and signaling. Curr Trends Immunol 19: 33-40

Gurkar AU, Chu K, Raj L, Bouley R, Lee S-H, Kim Y-B, Dunn SE, Mandinova A \& Lee SW (2013) Identification of ROCK1 kinase as a critical regulator of Beclin1-mediated autophagy during metabolic stress. Nat Commun 4: 2189

Gustafson EA \& Wessel GM (2010) DEAD-box helicases: posttranslational regulation and function. Biochem Biophys Res Commun 395: 1-6 
Hardy SD, Shinde A, Wang W-H, Wendt MK \& Geahlen RL (2017) Regulation of epithelialmesenchymal transition and metastasis by TGF- $\beta$, P-bodies, and autophagy. Oncotarget 8: 103302-103314

He X, Zhu Y, Zhang Y, Geng Y, Gong J, Geng J, Zhang P, Zhang X, Liu N, Peng Y, et al (2019) RNF 34 functions in immunity and selective mitophagy by targeting MAVS for autophagic degradation . EMBO J 38

Hubstenberger A, Courel M, Bénard M, Souquere S, Ernoult-Lange M, Chouaib R, Yi Z, Morlot J-B, Munier A, Fradet M, et al (2017) P-Body Purification Reveals the Condensation of Repressed mRNA Regulons. Mol Cell 68: 144-157.e5

Ichimura Y, Kumanomidou T, Sou Y, Mizushima T, Ezaki J, Ueno T, Kominami E, Yamane T, Tanaka K \& Komatsu M (2008) Structural basis for sorting mechanism of p62 in selective autophagy. J Biol Chem 283: 22847-57

Jin S, Tian S, Luo M, Xie W, Liu T, Duan T, Wu Y \& Cui J (2017) Tetherin Suppresses Type I Interferon Signaling by Targeting MAVS for NDP52-Mediated Selective Autophagic Degradation in Human Cells. Mol Cell 68: 308-322.e4

Johnston BP, Pringle ES \& McCormick C (2019) KSHV activates unfolded protein response sensors but suppresses downstream transcriptional responses to support lytic replication. PLoS Pathog 15

Kabeya Y (2000) LC3, a mammalian homologue of yeast Apg8p, is localized in autophagosome membranes after processing. EMBO J 19: 5720-5728

Katayama H, Yamamoto A, Mizushima N, Yoshimori T \& Miyawaki A (2008) GFP-like proteins stably accumulate in lysosomes. Cell Struct Funct 33: 1-12

Kayyali US, Pennella CM, Trujillo C, Villa O, Gaestel M \& Hassoun PM (2002) Cytoskeletal changes in hypoxic pulmonary endothelial cells are dependent on MAPK-activated protein kinase MK2. J Biol Chem 277: 42596-42602

Kenific CM, Stehbens SJ, Goldsmith J, Leidal AM, Faure N, Ye J, Wittmann T \& Debnath J (2016) NBR 1 enables autophagy-dependent focal adhesion turnover. J Cell Biol 212: 577590

Klionsky DJ, Abdalla FC, Abeliovich H, Abraham RT, Acevedo-Arozena A, Adeli K, Agholme L, Agnello M, Agostinis P, Aguirre-Ghiso JA, et al (2012) Guidelines for the use and interpretation of assays for monitoring autophagy. Autophagy 8: 445-544

Kuma A, Hatano M, Matsui M, Yamamoto A, Nakaya H, Yoshimori T, Ohsumi Y, Tokuhisa T \& Mizushima N (2004) The role of autophagy during the early neonatal starvation period. Nature 432: 1032-1036

Lai WS \& Blackshear PJ (2001) Interactions of CCCH zinc finger proteins with mRNA. Tristetraprolin-mediated AU-rich element-dependent mRNA degradation can occur in the absence of a poly(A) tail. J Biol Chem 276: 23144-23154

Lai WS, Carballo E, Strum JR, Kennington EA, Phillips RS \& Blackshear PJ (1999) Evidence that Tristetraprolin Binds to AU-Rich Elements and Promotes the Deadenylation and 
Destabilization of Tumor Necrosis Factor Alpha mRNA. Mol Cell Biol 19: 4311-4323

Lane BR, Liu J, Bock PJ, Schols D, Coffey MJ, Strieter RM, Polverini PJ \& Markovitz DM (2002) Interleukin-8 and growth-regulated oncogene alpha mediate angiogenesis in Kaposi's sarcoma. J Virol 76: 11570-83

Lazarou M, Sliter DA, Kane LA, Sarraf SA, Wang C, Burman JL, Sideris DP, Fogel AI \& Youle RJ (2015) The ubiquitin kinase PINK1 recruits autophagy receptors to induce mitophagy. Nature 524: 309-314

Lee J-S, Li Q, Lee J-Y, Lee S-H, Jeong JH, Lee H-R, Chang H, Zhou F-C, Gao S-J, Liang C, et al (2009) FLIP-mediated autophagy regulation in cell death control. Nat Cell Biol 11: 13551362

Leidal AM, Cyr DP, Hill RJ, Lee PWK \& McCormick C (2012) Subversion of autophagy by Kaposi's sarcoma-associated herpesvirus impairs oncogene-induced senescence. Cell Host Microbe 11: 167-180

Levine B, Sinha S \& Kroemer G (2008) Bcl-2 family members: Dual regulators of apoptosis and autophagy. Autophagy 4: 600-606 doi:10.4161/auto.6260 [PREPRINT]

Liu J \& Debnath J (2016) The Evolving, Multifaceted Roles of Autophagy in Cancer. In Advances in Cancer Research pp 1-53. Academic Press Inc.

Liu Q, Xu C, Kirubakaran S, Zhang X, Hur W, Liu Y, Kwiatkowski NP, Wang J, Westover KD, Gao P, et al (2013) Characterization of Torin2, an ATP-competitive inhibitor of mTOR, ATM, and ATR. Cancer Res 73: 2574-2586

Luo Y, Na Z \& Slavoff SA (2018) P-Bodies: Composition, Properties, and Functions. Biochemistry 57: 2424

Maitra S, Chou CF, Luber CA, Lee KY, Mann M \& Chen CY (2008) The AU-rich element mRNA decay-promoting activity of BRF1 is regulated by mitogen-activated protein kinaseactivated protein kinase 2. RNA 14: 950-959

Maiuri MC \& Kroemer G (2015) Autophagy in stress and disease. Cell Death Differ 22: 365366 doi:10.1038/cdd.2014.236 [PREPRINT]

Mauvezin C \& Neufeld TP (2015) Bafilomycin A1 disrupts autophagic flux by inhibiting both V-ATPase-dependent acidification and Ca-P60A/SERCA-dependent autophagosomelysosome fusion. Autophagy 11: 1437-1438

McCormick C \& Ganem D (2005) The Kaposin B Protein of KSHV Activates the p38/MK2 Pathway and Stabilizes Cytokine mRNAs. Science (80- ) 307: 739-741

Miles SA, Rezai AR, Salazar-González JF, Vander Meyden M, Stevens RH, Logan DM, Mitsuyasu RT, Taga T, Hirano T \& Kishimoto T (1990) AIDS Kaposi sarcoma-derived cells produce and respond to interleukin 6. Proc Natl Acad Sci U S A 87: 4068-72

Mizushima N, Yoshimori T \& Levine B (2010) Methods in Mammalian Autophagy Research. Cell 140: 313-326 doi:10.1016/j.cell.2010.01.028 [PREPRINT]

Mohamud Y, Qu J, Xue YC, Liu H, Deng H \& Luo H (2019) CALCOCO2/NDP52 and 
SQSTM1/p62 differentially regulate coxsackievirus B3 propagation. Cell Death Differ 26: $1062-1076$

Morishita H \& Mizushima N (2019) Diverse cellular roles of autophagy. Annu Rev Cell Dev Biol 35: 453-475 doi:10.1146/annurev-cellbio-100818-125300 [PREPRINT]

Morriswood B, Ryzhakov G, Puri C, Arden SD, Roberts R, Dendrou C, Kendrick-Jones J \& Buss F (2007) T6BP and NDP52 are myosin VI binding partners with potential roles in cytokine signalling and cell adhesion. $J$ Cell Sci 120: 2574-85

Myoung J \& Ganem D (2011) iSLK cell. J Virol Methods 174: 12-21

Noda NN, Kumeta H, Nakatogawa H, Satoo K, Adachi W, Ishii J, Fujioka Y, Ohsumi Y \& Inagaki F (2008) Structural basis of target recognition by Atg8/LC3 during selective autophagy. Genes to Cells 13: 1211-1218

Noda NN, Ohsumi Y \& Inagaki F (2010) Atg8-family interacting motif crucial for selective autophagy. FEBS Lett 584: 1379-1385

Padman BS, Nguyen TN, Uoselis L, Skulsuppaisarn M, Nguyen LK \& Lazarou M (2019) LC3/GABARAPs drive ubiquitin-independent recruitment of Optineurin and NDP52 to amplify mitophagy. Nat Commun 10: 1-13

Prabakaran T, Bodda C, Krapp C, Zhang B, Christensen MH, Sun C, Reinert L, Cai Y, Jensen SB, Skouboe MK, et al (2018) Attenuation of c GAS - STING signaling is mediated by a p62/ SQSTM 1-dependent autophagy pathway activated by TBK1 . EMBO J 37

Pringle ES, Robinson C-A \& McCormick C (2019) Kaposi’s Sarcoma-Associated Herpesvirus Lytic Replication Interferes with mTORC1 Regulation of Autophagy and Viral Protein Synthesis. J Virol 93

Rahman H, Qasim M, Oellerich M \& Asif AR (2014) Crosstalk between Edc4 and mammalian target of rapamycin complex 1 (mTORC1) signaling in mRNA decapping. Int J Mol Sci 15: 23179-95

Riggs CL, Kedersha N, Ivanov P \& Anderson P (2020) Mammalian stress granules and P bodies at a glance. $J$ Cell Sci 133 doi:10.1242/jcs.242487 [PREPRINT]

Riva G, Barozzi P, Torelli G \& Luppi M (2010) Immunological and Inflammatory Features of Kaposi's Sarcom and Other Kaposi's Sarcoma-Associated Herpesvirus/Human Herpesvirus 8-Associated Neoplasias. AIDS Rev 9: 25-39

Rogov V, Dötsch V, Johansen T \& Kirkin V (2014) Interactions between Autophagy Receptors and Ubiquitin-like Proteins Form the Molecular Basis for Selective Autophagy. Mol Cell 53: $167-178$

Rousseau S, Houle F, Landry J \& Huot J (1997) P38 MAP kinase activation by vascular endothelial growth factor mediates actin reorganization and cell migration in human endothelial cells. Oncogene 15: 2169-2177

Sadagopan S, Sharma-Walia N, Veettil MV, Raghu H, Sivakumar R, Bottero V \& Chandran B (2007) Kaposi’s Sarcoma-Associated Herpesvirus Induces Sustained NF-кB Activation 
during De Novo Infection of Primary Human Dermal Microvascular Endothelial Cells That Is Essential for Viral Gene Expression. J Virol 81: 3949-3968

Salahuddin S, Nakamura S, Biberfeld P, Kaplan M, Markham P, Larsson L \& Gallo R (1988) Angiogenic properties of Kaposi's sarcoma-derived cells after long-term culture in vitro. Science (80- ) 242: 430-433

Sargsyan A, Cai J, Fandino LB, Labasky ME, Forostyan T, Colosimo LK, Thompson SJ \& Graham TE (2015) Rapid parallel measurements of macroautophagy and mitophagy in mammalian cells using a single fluorescent biosensor. Sci Rep 5

Seth RB, Sun L, Ea CK \& Chen ZJ (2005) Identification and characterization of MAVS, a mitochondrial antiviral signaling protein that activates NF- $\kappa B$ and IRF3. Cell 122: 669-682

Shen L, Qi Z, Zhu Y, Song X, Xuan C, Ben P, Lan L, Luo L \& Yin Z (2016) Phosphorylated heat shock protein 27 promotes lipid clearance in hepatic cells through interacting with STAT3 and activating autophagy. Cell Signal 28: 1086-1098

Soulier J, Grollet L, Oksenhendler E, Cacoub P, Cazals-Hatem D, Babinet P, d'Agay MF, Clauvel JP, Raphael M \& Degos L (1995) Kaposi's sarcoma-associated herpesvirus-like DNA sequences in multicentric Castleman's disease. Blood 86: 1276-80

Standart N \& Weil D (2018) P-Bodies: Cytosolic Droplets for Coordinated mRNA Storage. Trends Genet 34: 612-626 doi:10.1016/j.tig.2018.05.005 [PREPRINT]

Staskus KA, Zhong W, Gebhard K, Herndier B, Wang H, Renne R, Beneke J, Pudney J, Anderson DJ, Ganem D, et al (1997) Kaposi's sarcoma-associated herpesvirus gene expression in endothelial (spindle) tumor cells. $J$ Virol 71: 715-9

Sumpter R \& Levine B (2011) Selective autophagy and viruses. Autophagy 7: 260-265 doi:10.4161/auto.7.3.14281 [PREPRINT]

Tenekeci U, Poppe M, Beuerlein K, Busch J, Schmitz ML \& Kracht Correspondence M (2016) K63-Ubiquitylation and TRAF6 Pathways Regulate Mammalian P-Body Formation and mRNA Decapping. Mol Cell 62: 943-957

Thoreen CC, Kang SA, Won Chang J, Liu Q, Zhang J, Gao Y, Reichling LJ, Sim T, Sabatini DM \& Gray NS (2009) An ATP-competitive Mammalian Target of Rapamycin Inhibitor Reveals Rapamycin-resistant Functions of mTORC1 * $\square$ S. J Biol Chem 284: 8023-32

Till A, Lipinski S, Ellinghaus D, Mayr G, Subramani S, Rosenstiel P \& Franke A (2013) Autophagy receptor CALCOCO2/NDP52 takes center stage in Crohn disease. Autophagy 9: 1256-7

Tripathi DN, Zhang J, Jing J, Dere R \& Walker CL (2016) A new role for ATM in selective autophagy of peroxisomes (pexophagy). Autophagy 12: 711-712 doi:10.1080/15548627.2015.1123375 [PREPRINT]

Turakhiya A, Meyer SR, Marincola G, Böhm S, Vanselow JT, Schlosser A, Hofmann K \& Buchberger A (2018) ZFAND1 Recruits p97 and the 26S Proteasome to Promote the Clearance of Arsenite-Induced Stress Granules. Mol Cell 70: 906-919.e7 
Verlhac P, Gré IP, Viret C \& Faure M (2015) Autophagy Receptor NDP52 Regulates PathogenContaining Autophagosome Maturation. Cell Host Microbe 17: 515-525

Vescovo T, Pagni B, Piacentini M, Fimia GM \& Antonioli M (2020) Regulation of Autophagy in Cells Infected With Oncogenic Human Viruses and Its Impact on Cancer Development. Front Cell Dev Biol 8 doi:10.3389/fcell.2020.00047 [PREPRINT]

Vieira J \& O’Hearn PM (2004) Use of the red fluorescent protein as a marker of Kaposi's sarcoma-associated herpesvirus lytic gene expression. Virology 325: 225-240

Vindry C, Marnef A, Broomhead H, Twyffels L, Ozgur S, Stoecklin G, Llorian M, Smith CW, Mata J, Weil D, et al (2017) Dual RNA Processing Roles of Pat1b via Cytoplasmic Lsm1-7 and Nuclear Lsm2-8 Complexes. Cell Rep 20: 1187-1200

Wei Y, An Z, Zou Z, Sumpter R, Su M, Zang X, Sinha S, Gaestel M \& Levine B (2015) The stress-responsive kinases MAPKAPK2/MAPKAPK3 activate starvation-induced autophagy through Beclin 1 phosphorylation. Elife 4

Wen KW \& Damania B (2010) Kaposi sarcoma-associated herpesvirus (KSHV): molecular biology and oncogenesis. Cancer Lett 289: 140-50

Wu WKK, Coffelt SB, Cho CH, Wang XJ, Lee CW, Chan FKL, Yu J \& Sung JJY (2012) The autophagic paradox in cancer therapy. Oncogene 31: 939-953 doi:10.1038/onc.2011.295 [PREPRINT]

Wu Y, Jin S, Liu Q, Zhang Y, Ma L, Zhao Z, Yang S, Li YP \& Cui J (2020) Selective autophagy controls the stability of transcription factor IRF3 to balance type I interferon production and immune suppression. Autophagy

Xie X, Li F, Wang Y, Wang Y, Lin Z, Cheng X, Liu J, Chen C \& Pan L (2015) Molecular basis of ubiquitin recognition by the autophagy receptor CALCOCO2. Autophagy 11: 1775-89

Yang Q, Liu TT, Lin H, Zhang M, Wei J, Luo WW, Hu YH, Zhong B, Hu MM \& Shu HB (2017) TRIM32-TAX1BP1-dependent selective autophagic degradation of TRIF negatively regulates TLR3/4-mediated innate immune responses. PLoS Pathog 13

Yao Z \& Klionsky DJ (2016) An unconventional pathway for mitochondrial protein degradation. Autophagy 12: 1971-1972 doi:10.1080/15548627.2016.1235127 [PREPRINT]

Yoon J-H, Choi E-J \& Parker R (2010) Dcp2 phosphorylation by Ste20 modulates stress granule assembly and mRNA decay in Saccharomyces cerevisiae. J Cell Biol 189: 813-27

Youn JY, Dunham WH, Hong SJ, Knight JDR, Bashkurov M, Chen GI, Bagci H, Rathod B, MacLeod G, Eng SWM, et al (2018) High-Density Proximity Mapping Reveals the Subcellular Organization of mRNA-Associated Granules and Bodies. Mol Cell 69: 517532.e11

Young ARJ, Narita M, Ferreira M, Kirschner K, Sadaie M, Darot JFJ, Tavaré S, Arakawa S, Shimizu S, Watt FM, et al (2009) Autophagy mediates the mitotic senescence transition. Genes Dev 23: 798-803 
bioRxiv preprint doi: https://doi.org/10.1101/2021.02.07.430164; this version posted June 21, 2021. The copyright holder for this preprint (which was not certified by peer review) is the author/funder, who has granted bioRxiv a license to display the preprint in perpetuity. It is made available under aCC-BY 4.0 International license.

830

831 


\section{Figure Legends}

Figure 1: Kaposin B requires canonical autophagy to disassemble PBs. Primary human umbilical vein endothelial cells (HUVECs) were transduced with recombinant lentiviruses expressing either Kaposin B (KapB) or an empty vector control and selected with blasticidin (5 $\mu \mathrm{g} / \mathrm{mL})$. A: Cells were treated with bafilomycin A1 (10 nM) or a vehicle control (DMSO) for the indicated times prior to harvest in 2x Laemmli buffer. Protein lysates were resolved by SDSPAGE and immunoblot was performed for p62 and LC3. Samples were quantified using Image Lab (Biorad) software and then normalized, first to total protein and then to their respective starting time points $(0 \mathrm{~h})$. Results were plotted in GraphPad and a linear regression statistical test was performed, \pm SEM; $\mathrm{n}=3, *=\mathrm{P}<0.05, * * *=\mathrm{P}<0.001$. B: Cells were treated with BafA1 for 30 min prior to fixation in methanol. Immunofluorescence was performed for LC3 (white) and DAPI (nuclei, blue). Scale bar=20 $\mu \mathrm{m}$. Total LC3 area per field was quantified by identifying LC3-positive puncta using CellProfiler and normalizing to the number of nuclei and the vector DMSO control. Results were plotted in GraphPad, a 2-way ANOVA was performed with a Šidák's multiple comparison test, \pm SEM; $n=3, *=P<0.05$. C: HUVECs were sequentially transduced: first with recombinant lentiviruses expressing either shRNAs targeting Atg5 or Atg14 (shAtg5, shAtg14) or a non-targeting control (NS) and selected with puromycin (1 $\mu \mathrm{g} / \mathrm{mL})$, and second with either KapB or an empty vector control and selected with blasticidin (5 $\mu \mathrm{g} / \mathrm{mL}$ ). Coverslips were fixed in $4 \%$ paraformaldehyde, permeabilized in $0.1 \%$ Triton X-100, and immunostained for the PB-resident protein Hedls (white) and nuclei (DAPI). Scale bar=20 $\mu \mathrm{m}$. Hedls puncta were quantified using CellProfiler and normalized to the number of nuclei, results were plotted in GraphPad and a 2-way ANOVA was performed with a Šidák's multiple comparison test, \pm SEM; $\mathrm{n}=3, *=\mathrm{P}<0.05$. D: HUVECs were transduced as in A and treated with 
855 DMSO or bafilomycin A1 (10 nM) for $30 \mathrm{~min}$ before being fixed in 4\% paraformaldehyde and 856 permeabilized in $0.1 \%$ Triton X-100. Immunofluorescence was performed for Hedls (PBs,

857 white) and DAPI (nuclei, blue). Scale bar $=20 \mu \mathrm{m}$. Hedls puncta were counted using CellProfiler 858 and normalized to the number of nuclei, results were plotted in GraphPad and a 2-way ANOVA was performed with a Šidák’s multiple comparison test, $\pm \mathrm{SEM}$; $\mathrm{n}=3, *=\mathrm{P}<0.05$.

Figure 2: Torin treatment disassembles PBs. A: HUVECs were treated with either Torin (250 $\mathrm{nM}$ ) or a DMSO control for $2 \mathrm{~h}$ prior to fixation in $4 \%$ paraformaldehyde. Samples were permeabilized in $0.1 \%$ Triton $\mathrm{X}-100$. Immunofluorescence was performed for Hedls (PBs, white) and DAPI (nuclei, blue). Scale bar=20 $\mu \mathrm{m}$. Hedls puncta were counted using CellProfiler

864 and normalized to the number of nuclei, results were plotted in GraphPad and a 2-way ANOVA was performed with a Šidák's multiple comparison test, \pm SEM; $n=3, *=\mathrm{P}<0.05$. B: HUVECs were treated with either Torin $(250 \mathrm{nM})$ or a DMSO control for 90 min prior to the addition of sodium arsenite $(0.25 \mathrm{mM})$ for $30 \mathrm{~min}$. Cells were fixed in $4 \%$ paraformaldehyde and permeabilized in $0.1 \%$ Triton X-100. Immunofluorescence was performed for Hedls (PBs, white) and DAPI (nuclei, blue). Scale bar $=20 \mu \mathrm{m}$. C: HUVECs were transduced with recombinant lentiviruses expressing either shRNAs targeting Atg5 (shAtg5) or a non-targeting

871 control (NS) and selected with puromycin $(1 \mu \mathrm{g} / \mathrm{mL})$. Cells were treated with Torin $(250 \mathrm{nM})$ or 872 DMSO for $2 \mathrm{~h}$ prior to fixation in in $4 \%$ paraformaldehyde and permeabilization in $0.1 \%$ Triton

873 X-100. Samples were immunostained for the PB-resident protein Hedls (white) and nuclei 874 (DAPI). Scale bar $=20 \mu \mathrm{m}$. Hedls puncta were quantified using CellProfiler and normalized to 875 the number of nuclei, results were plotted in GraphPad and a 2-way ANOVA was performed 876 with a Šidák’s multiple comparison test, \pm SEM; $\mathrm{n}=4$, * $=\mathrm{P}<0.05$. 
877 Figure 3: KapB-mediated ARE-mRNA reporter expression requires canonical autophagy.

878 A: HUVECs were transduced with recombinant lentiviruses expressing either KapB or an empty

879 vector control and selected with blasticidin $(5 \mu \mathrm{g} / \mathrm{mL})$. Conditioned media harvested from

880 KSHV latently infected cells was used to mimic the KS lesion microenvironment and induce the

881

882

883

884

885

886

887

888

889

890

891

892

893

894

895

896

897

898

899 transcription of cytokines for $6 \mathrm{~h}$ prior to lysis for total RNA, normal media was used for the $0 \mathrm{~h}$ time point. Transcript levels were quantified by qPCR and normalized to $18 \mathrm{~S}$ as a reference gene. Data is represented as the fold change in target transcript expression relative to the untreated vector control and was quantified using the $\Delta \Delta \mathrm{Cq}$ method. Results were plotted in GraphPad, a 2-way ANOVA was performed, $\pm \mathrm{SEM}$; $\mathrm{n}=3, *=\mathrm{P}<0.05, * *=\mathrm{P}<0.01$. B: HUVECs were treated with Torin $(250 \mathrm{nM})$ or a DMSO control for $2 \mathrm{~h}$ prior to lysis for total RNA. Transcript levels were quantified by qPCR and normalized to HPRT as a reference gene. Data is represented as the fold change in target transcript expression relative to the untreated vector control and was quantified using the $\Delta \Delta \mathrm{Cq}$ method. An unpaired t-test was performed, $\pm \mathrm{SEM}$; $\mathrm{n}=3, *=\mathrm{P}<0.05$. C: HeLa Tet-Off cells were co-transfected with expression plasmids for an ARE-containing firefly luciferase plasmid (pTRE-Fluc-ARE) and a stable renilla luciferase plasmid (pTRE-Rluc). $36 \mathrm{~h}$ post transfection, doxycycline (Dox) was added to halt reporter gene transcription of both luciferase reporters, at the same time Torin $(250 \mathrm{nM})$ or DMSO were added; $12 \mathrm{~h}$ after Dox addition, lysates were harvested in passive lysis buffer (Promega). Luciferase activity for both firefly and renilla was analyzed using the Dual-Luciferase Reporter Assay (Promega) and normalized (firefly/renilla) relative luciferase was calculated in relative light units (RLUs). Results were plotted using GraphPad, an unpaired t-test was performed, \pm SEM; $\mathrm{n}=6$, $* * *=\mathrm{P}<0.001 . \mathrm{D} \& \mathrm{E}:$ HeLa Tet-Off cells were transduced with recombinant lentiviruses expressing either shRNAs targeting Atg5 or Atg14 (shAtg5, shAtg14) or a non-targeting control 
(NS) and selected with puromycin $(1 \mu \mathrm{g} / \mathrm{mL})$. After selection, cells were co-transfected and Dox treatment was performed as described in C, except that co-transfection also included an expression plasmid for KapB or an empty vector control. Results were plotted using GraphPad, an unpaired t-test was performed, $\pm \mathrm{SEM} ; \mathrm{n}=3, *=\mathrm{P}<0.05, * *=\mathrm{P}<0.01$. F: Cells were cotransfected as in E and bafilomycin $(10 \mathrm{nM})$ was added at the same time as Dox. Results were plotted in GraphPad and a Student's t-test was performed, $\pm \mathrm{SEM} ; \mathrm{n}=3, *=\mathrm{P}<0.05, * *=\mathrm{P}<0.01$.

\section{Figure 4: Dcp1a protein levels are decreased by KapB expression and Torin treatment. A:}

HUVECs were treated with DMSO or Torin $(250 \mathrm{nM})$ for $4 \mathrm{~h}$ prior to harvest. Samples were lysed in 2x Laemmli buffer and resolved by SDS-PAGE before immunoblotting with Xrn1, EDC4/Hedls, Dcp1a, and DDX6. Samples were quantified by normalizing the PB resident protein levels to the total protein in each lane and then the DMSO control using ImageLab (Biorad). Results were plotted in GraphPad and a one-way ANOVA was performed \pm SEM; $n=3$, $* *=\mathrm{P}<0.01$. B: HUVECs were transduced with recombinant lentiviruses expressing either KapB or an empty vector control and selected with blasticidin $(5 \mu \mathrm{g} / \mathrm{mL})$. Cells were treated with DMSO or bafilomycin A1 (BafA1, $10 \mathrm{nM}$ ) for $4 \mathrm{~h}$ prior to harvest in 2x Laemmli buffer. Samples were resolved by SDS-PAGE and immunoblot was performed for Dcp1a or p62 (autophagy marker). Samples were quantified by normalizing Dcpla protein levels to the total protein in each lane using Image Lab (Biorad) and then to the Vector DMSO control. Results were plotted in GraphPad and a 2-way ANOVA was performed, $\pm \mathrm{SEM}$; $=3, * * *=\mathrm{P}<0.001$. C: HUVECs were transduced with recombinant lentiviruses expressing either KapB or an empty vector control and selected with blasticidin $(5 \mu \mathrm{g} / \mathrm{mL})$. Samples were harvested in 2x Laemmli buffer, resolved by SDS-PAGE and immunoblot was performed for Xrn1, Hedls/EDC4, or 
923 lane using Image Lab (Biorad) and then to the Vector DMSO control. Results were plotted in

924 GraphPad. D: HUVECs were sequentially transduced: first with recombinant lentiviruses

925 expressing either shRNAs targeting Atg5 (shAtg5) or a non-targeting control (NS) and selected

926 with puromycin $(1 \mu \mathrm{g} / \mathrm{mL})$, and second with either KapB or an empty vector control and selected

927 with blasticidin $(5 \mu \mathrm{g} / \mathrm{mL})$. Samples were harvested in $2 x$ Laemmli buffer and resolved by SDS-

928 PAGE. Immunoblot was performed for Dcp1a, Atg5, and KapB. Samples were quantified by

929 normalizing Dcpla protein levels to the total protein in each lange using Image Lab (Biorad) and

930 then to the Vector NS control. Results were plotted in GraphPad and a 2-way ANOVA was

931 performed, \pm SEM; $\mathrm{n}=3, *=\mathrm{P}<0.05, * * \mathrm{P}=<0.01$.

932 Figure 5. KapB-mediated PB disassembly and ARE-mRNA reporter expression require the

933 selective autophagy receptor NDP52. A: HUVECs were sequentially transduced with

934 recombinant lentivirus expressing $\mathrm{KapB}$ or an empty vector control and selected with blasticidin

$935(5 \mu \mathrm{g} / \mathrm{mL})$, and second with shRNAs targeting NDP52, OPTN, p62 or a non-targeting control

936 (NS) and selected with puromycin $(1 \mu \mathrm{g} / \mathrm{mL})$. Coverslips were fixed in 4\% paraformaldehyde,

937 permeabilized in $0.1 \%$ Triton X-100 and immunostained for Hedls (PBs; white), DAPI (nuclei,

938 blue). Scale bar $=20 \mu \mathrm{m}$. Cells were imaged and the mean number of Hedls puncta per cell were

939 quantified using CellProfiler. Data were plotted in GraphPad as the mean number of Hedls

940 puncta per cell per condition \pm SEM; n=3. A 2-way ANOVA was performed with a Šidák’s

941 multiple comparison test; $*=\mathrm{P}<0.05 * *=\mathrm{P}<0.01$. B: HUVECs were transduced with

942 recombinant lentivirus expressing an shRNA targeting NDP52 and selected with puromycin (1

$943 \mu \mathrm{g} / \mathrm{mL})$. Cells were treated with Torin $(250 \mathrm{nM})$ or a DMSO control for $2 \mathrm{~h}$ prior to fixation in

$944 \quad 4 \%$ paraformaldehyde and permeabilization in $0.1 \%$ Triton X-100. Samples were

945 immunostained for Hedls (PBs; white), DAPI (nuclei, blue). Scale bar $=20 \mu \mathrm{m}$. Cells were 
946 imaged and the mean number of Hedls puncta per cell were quantified using CellProfiler. Data

947 were plotted in GraphPad as the mean number of Hedls puncta per cell per condition. Results

948 were plotted in GraphPad, a 2-way ANOVA was performed with a Šidák's multiple comparison

949 test, $\pm \mathrm{SEM} ; \mathrm{n}=3 . *=\mathrm{P}<0.05 . \mathrm{C}:$ HeLa Tet-Off cells were transduced with recombinant

950 lentivirus expressing shRNAs targeting NDP52, OPTN, p62 or a NS control and selected with

951 puromycin $(1 \mu \mathrm{g} / \mathrm{mL})$ then cells were co-transfected, treated with Dox and luciferase activity was

952 recorded and analyzed as in Figure 3. Data were plotted in GraphPad as the mean fold change in

953 the relative luciferase activity of each condition compared to vector NS or KapB NS; $n=3$. An

954 unpaired t-test was performed; $*=\mathrm{P}<0.05 * *=\mathrm{P}<0.01$. D: Schematic of NDP52. NDP52

955 contains the following domains and interacting regions: SKICH domain (SKIP-carboxyl

956 homology domain), CLIR (non-canonical LC3-interaction motif), coiled-coil domain, GALB

957 (galectin binding domain) ZF1 \& ZF2 (zinc finger domains). Known mutations that disrupt

958 NDP52 function include: V136S which prevents binding to LC3-C and C443K which prevents

959 binding to ubiquitin. E: HUVECs were sequentially transduced first with recombinant lentivirus

960 expressing shDNP52 targeting the 3'-UTR of NDP52 or a NS control and selected with

961 blasticidin $(5 \mu \mathrm{g} / \mathrm{mL})$, and second, with $\mathrm{KapB}$ and one of the following: mCherry control (mCh),

962 RFP-NDP52 wt, mCh-NDP52 C443K or mCh-NDP52 V136S/C443K. Coverslips were fixed

963 with 4\% paraformaldehyde, permeabilized with $0.1 \%$ Triton X-100, and immunostained with

964 Hedls (PBs, green). Scale bar=20 $\mu \mathrm{m}$. F: Samples from E were quantified; Hedls puncta were

965 counted using CellProfiler and normalized to the number of nuclei, results were plotted in

966 GraphPad, a 2-way ANOVA was performed with a Šidák’s multiple comparison test, \pm SEM;

$967 \mathrm{n}=3 . *=\mathrm{P}<0.05, * *=\mathrm{P}<0.01$. 


\section{Figure 6: MK2EE-mediated PB disassembly does not require NDP52 or canonical}

autophagy. A: HUVECs were transduced with recombinant lentiviruses expressing either constitutively active MK2 (MK2EE) or an empty vector control and selected with blasticidin (5 $\mu \mathrm{g} / \mathrm{mL}$ ) for $48 \mathrm{~h}$. Cells were treated with DMSO or bafilomycin A1 (10 $\mathrm{nM})$ for 30 min before being fixed in methanol. Immunofluorescence was performed for LC3 (autophagosomes, white) and DAPI (nuclei, blue). Scale bar $=20 \mu \mathrm{m}$. Total LC3 area per field was quantified by identifying LC3 puncta using CellProfiler and normalizing to the number of nuclei and the vector DMSO control. Results were plotted in GraphPad and a 2-way ANOVA was performed with a Šidák's multiple comparison test, $\pm \mathrm{SEM} \mathrm{n}=3 ; *=\mathrm{P}<0.05$. B: HUVECs were transduced with recombinant lentiviruses expressing either MK2EE or an empty vector control and selected with blasticidin $(5 \mu \mathrm{g} / \mathrm{mL})$. Cells were treated with bafilomycin A1 (10 $\mathrm{nM})$ or a vehicle control (DMSO) for the indicated times prior to harvest in $2 \mathrm{x}$ Laemmli buffer. Protein lysates were resolved by SDS-PAGE and immunoblot was performed for p62 and LC3. Samples were quantified using Image Lab (Biorad) software and then normalized, first to total protein and then to their respective starting points (time $0 \mathrm{~h}$ ). Results were plotted in GraphPad and a linear regression statistical test was performed, \pm SEM; $n=3, *=P<0.05, * *=P<0.01$. C: HUVECs were sequentially transduced: first with recombinant lentiviruses expressing either shRNAs targeting Atg5 (shAtg5) or a non-targeting control (NS) and selected with puromycin $(1 \mu \mathrm{g} / \mathrm{mL})$, and second, with either MK2EE or an empty vector control and selected with blasticidin $(5 \mu \mathrm{g} / \mathrm{mL})$. Coverslips were fixed in 4\% paraformaldehyde, permeabilized in $0.1 \%$ Triton X-100, and immunostained for the PB-resident protein Hedls (PBs, white) and DAPI (nuclei, blue). Scale bar $=20 \mu \mathrm{m}$. Hedls puncta were counted using CellProfiler and normalized to the number of nuclei, results were plotted in GraphPad and a 2-way ANOVA was performed with a Šidák's 
multiple comparison test, \pm SEM $n=5 ; *=\mathrm{P}<0.05$. D: HeLa Tet-Off cells were transduced with recombinant lentiviruses expressing either shRNAs targeting Atg5 (shAtg5) or a non-targeting control (NS) and selected with puromycin $(1 \mu \mathrm{g} / \mathrm{mL})$ then co-transfected with expression plasmids for pTRE-Fluc-ARE, pTRE-Rluc, and MK2EE or an empty vector control, and treated as in Figure 3. Results were plotted using GraphPad, a Student's t-test was performed, $\pm \mathrm{SEM}$, $\mathrm{n}=4 ; *=\mathrm{P}<0.05$. E: HUVECs were sequentially transduced with recombinant lentivirus expressing shRNAs targeting NDP52, OPTN, p62 or a non-targeting control (NS) and selected with puromycin $(1 \mu \mathrm{g} / \mathrm{mL})$ and second with recombinant lentivirus expressing constitutively active MK2EE or an empty vector control and selected with blasticidin $(5 \mu \mathrm{g} / \mathrm{mL})$. Coverslips were fixed in $4 \% \mathrm{v} / \mathrm{v}$ paraformaldehyde, permeabilized in $0.1 \%$ Triton $\mathrm{X}-100$, and immunostained for Hedls (PBs, white) and DAPI (nuclei, blue). Scale bar $=20 \mu \mathrm{m}$. Hedls puncta were counted using CellProfiler and normalized to the number of nuclei, results were plotted in GraphPad, \pm SEM; n=3. F: HeLa Tet-Off cells were transduced with recombinant lentivirus expressing shRNAs targeting NDP52, OPTN, p62 or a NS control and selected with puromycin $(1 \mu \mathrm{g} / \mathrm{mL})$ then cells were co-transfected, treated with Dox and luciferase activity was recorded and analyzed as in Figure 3. Data were plotted in GraphPad as the mean fold change in the relative luciferase activity of each condition compared to vector NS or MK2EE NS; $n=3$. An unpaired t-test was performed; $*=\mathrm{P}<0.05 * *=\mathrm{P}<0.01$.

Figure 7: Model of NDP52-dependent PB disassembly elicited by KapB. A: KapB expression has the potential to impact two pathways that lead to PB disassembly, thereby increasing the stability/translation of AU-rich containing inflammatory cytokine mRNA. The first pathway is dependent on canonical autophagy and the SAR, NDP52, and is also used to elicit PB disassembly by the mTOR inhibitor, Torin. Because of its ability to bind and activate MK2, 
1014 KapB also may promote PB disassembly using an autophagy-independent pathway that relies on 1015 phosphorylated, active MK2, a pathway that is mimicked by overexpression of MK2EE. B:

1016 Under normal conditions, the cytoplasm of all cells contain PBs, granules comprised of RNA and 1017 RNA decay proteins that are visible by immunofluorescent microscopy. When KapB is 1018 expressed, microscopically visible PBs are lost but can reform after overexpression of Dcpla1019 GFP or after stress-induced translation shutoff. PB disassembly elicited by KapB depends on the 1020 selective autophagy receptor, NDP52. KapB expression decreases the steady-state level of the 1021 PB protein, Dcp1a, but does not markedly alter the levels of other PB proteins like DDX6, 1022 ECD4/Hedls, or Xrn1. Dcp1a has been shown to be modified by phosphorylation and 1023 ubiquitination (Tenekeci et al, 2016; Aizer et al, 2013; Chiang et al, 2013) and these 1024 modifications alter PB formation and function. These data lead us to propose the following

1025

1026

1027

1028

1029

1030

1031

1032

1033

1034

1035

1036 model. KapB expression leads to an as yet undetermined post-translational modification that promotes its recognition by the selective autophagy receptor, NDP52. Simultaneous binding of NDP52 to modified Dcpla (or another unidentified PB protein) and to LC3 on the nascent phagophore recruit Dcpla to the autophagosome for degradation. The loss of Dcpla or another $\mathrm{PB}$ protein via selective autophagy leads to $\mathrm{PB}$ disassembly but does not prevent de novo $\mathrm{PB}$ assembly under stress, even during KapB expression.

DDX6/Rck: RNA helicase, EDC4/Hedls: decapping co-factor, Dcp2: catalytic component of decapping machinery, Dcp1a: decapping co-factor, ECD3: decapping enhancer, Xrn1: 3'-5' exonuclease. 
$\underline{\text { Tables }}$

Table 1: Drugs

\begin{tabular}{|l|l|l|}
\hline Drug & Vendor/Catalogue \# & Concentration \\
\hline Torin1 & Sigma-Aldrich 475991 & $250 \mathrm{nM}$ \\
\hline Bafilomycin A1 & Sigma-Aldrich B1793 & $10 \mathrm{nM}$ \\
\hline Chloroquine & Sigma-Aldrich C6628 & $25 \mu \mathrm{M}$ \\
\hline MG-132 & Selleckchem S2619 & $5 \mu \mathrm{M}$ \\
\hline LPS & Sigma-Aldrich L3129 & $1 \mu \mathrm{g} / \mathrm{mL}$ \\
\hline Sodium Arsenite & Sigma-Aldrich 1.06277 & $0.25 \mathrm{mM}$ \\
\hline Doxycycline & Sigma-Aldrich D9891 & $1 \mu \mathrm{g} / \mathrm{mL}$ \\
\hline
\end{tabular}

1041 Table 2: Plasmids

\begin{tabular}{|l|l|l|l|}
\hline Plasmid & Use & Source & $\begin{array}{l}\text { Mammalian } \\
\text { Selection }\end{array}$ \\
\hline $\begin{array}{l}\text { pBMN mCh } \\
\text { NDP52 C443K }\end{array}$ & UBD mutant & $\begin{array}{l}\text { Addgene \#119685 } \\
\text { (Padman et al., 2019) }\end{array}$ & N/A \\
\hline $\begin{array}{l}\text { pBMN mCh } \\
\text { NDP52 C443K } \\
\text { V136S }\end{array}$ & $\begin{array}{l}\text { UBD/LIR } \\
\text { mutant }\end{array}$ & $\begin{array}{l}\text { Addgene \#119686 } \\
\text { (Padman et al., 2019) }\end{array}$ & N/A \\
\hline RFP-NDP52 & Overexpression & $\begin{array}{l}\text { Dr. Andreas Till (University Hospital } \\
\text { of Bonn) }\end{array}$ & N/A \\
\hline pcDNA 3.1 (+) & $\begin{array}{l}\text { Empty Vector } \\
\text { Control }\end{array}$ & Invitrogen V79020 & N/A \\
\hline $\begin{array}{l}\text { pcDNA KapB } \\
\text { BCBL1 }\end{array}$ & $\begin{array}{l}\text { ARE-mRNA } \\
\text { stability }\end{array}$ & (Corcoran et al., 2015) & N/A \\
\hline $\begin{array}{l}\text { pcDNA FLAG- } \\
\text { MK2EE }\end{array}$ & $\begin{array}{l}\text { ARE-mRNA } \\
\text { stability }\end{array}$ & $\begin{array}{l}\text { (Corcoran et al., 2015) } \\
\text { pLKO.1-TRC } \\
\text { expression }\end{array}$ & $\begin{array}{l}\text { Addgene \#10878 } \\
\text { (Moffat et al., 2006) }\end{array}$ \\
\hline pLKO.1-blast & $\begin{array}{l}\text { shRNA } \\
\text { expression }\end{array}$ & $\begin{array}{l}\text { Addgene \#26655 } \\
\text { (Bryant et al., 2010) }\end{array}$ & N/A \\
\hline pLJM1 & $\begin{array}{l}\text { Empty Vector } \\
\text { Control }\end{array}$ & (Johnston et al., 2019) & $\begin{array}{l}\text { Blasticidin } \\
\text { Puromycin }\end{array}$ \\
\hline $\begin{array}{l}\text { pLJM1 KapB } \\
\text { pulmonary KS) }\end{array}$ & Overexpression & $\begin{array}{l}\text { Cloned from pBMNIP-KapB (Corcoran } \\
\text { et al., 2015) into pLJM1-BSD }\end{array}$ & Blasticidin \\
\hline
\end{tabular}




\begin{tabular}{|c|c|c|c|}
\hline Plasmid & Use & Source & $\begin{array}{l}\text { Mammalian } \\
\text { Selection }\end{array}$ \\
\hline pLJM1 mCh & $\begin{array}{l}\text { Overexpression } \\
\text { Control }\end{array}$ & $\begin{array}{l}\text { Craig McCormick (Dalhousie } \\
\text { University) }\end{array}$ & Blasticidin \\
\hline $\begin{array}{l}\text { pLJM1 FLAG- } \\
\text { MK2EE }\end{array}$ & Overexpression & $\begin{array}{l}\text { Cloned into pLJM1 using BamHI and } \\
\text { EcoRI from pBMN FLAG-MK2EE } \\
\text { (Corcoran et al., 2015) }\end{array}$ & $\begin{array}{l}\text { Blasticidin/ } \\
\text { Puromycin }\end{array}$ \\
\hline $\begin{array}{l}\text { pLJM1 RFP- } \\
\text { NDP52 }\end{array}$ & Overexpression & $\begin{array}{l}\text { Cloned into pLJM1 using NheI and } \\
\text { BamHI from RFP-NDP52 }\end{array}$ & Puromycin \\
\hline $\begin{array}{l}\text { pLJM1 mCh- } \\
\text { NDP52 C443K }\end{array}$ & Overexpression & $\begin{array}{l}\text { Cloned into pLJM1 from Addgene } \\
\# 119685 \text { using the primers listed in } \\
\text { Table } 4\end{array}$ & $\begin{array}{l}\text { Blasticidin/ } \\
\text { Puromycin }\end{array}$ \\
\hline $\begin{array}{l}\text { pLJM1 mCh- } \\
\text { NDP52 C443K } \\
\text { V136S }\end{array}$ & Overexpression & $\begin{array}{l}\text { Cloned into pLJM1 from Addgene } \\
\# 119686 \text { using the primers listed in } \\
\text { Table } 4\end{array}$ & $\begin{array}{l}\text { Blasticidin/ } \\
\text { Puromycin }\end{array}$ \\
\hline pMD2.G & $\begin{array}{l}\text { Lentivirus } \\
\text { generation }\end{array}$ & Addgene \#12259 & $\mathrm{N} / \mathrm{A}$ \\
\hline psPAX2 & $\begin{array}{l}\text { Lentivirus } \\
\text { generation }\end{array}$ & Addgene $\# 12260$ & $\mathrm{~N} / \mathrm{A}$ \\
\hline $\begin{array}{l}\text { pTRE2 Firefly } \\
\text { Luciferase-ARE }\end{array}$ & $\begin{array}{l}\text { ARE-mRNA } \\
\text { stability }\end{array}$ & (Corcoran et al., 2011) & $\mathrm{N} / \mathrm{A}$ \\
\hline $\begin{array}{l}\text { pTRE2-Renilla } \\
\text { Luciferase }\end{array}$ & $\begin{array}{l}\text { ARE-mRNA } \\
\text { stability }\end{array}$ & (Corcoran et al., 2011) & $\mathrm{N} / \mathrm{A}$ \\
\hline
\end{tabular}

Table 3: shRNA target sequences

\begin{tabular}{|l|l|l|}
\hline shRNA target & shRNA sequence $\mathbf{5}^{\prime} \rightarrow \mathbf{3}^{\prime}$ & Region \\
\hline Non-targeting (NS) & AGCACAAGCTGGAGTACAACTA & \\
\hline Atg5 & CTTTGATAATGAACAGTGAGA & CDS \\
\hline NDP52(1) & GAGCTGCTTCAACTGAAAGAA & CDS \\
\hline NDP52(2) & GACTTGCCTATGGAAACCCAT & CDS \\
\hline NDP52(3) & CCCTTTGTGAACTAAGTTCAA & 3'-UTR \\
\hline NDP52(4) & CCTGACTTGATACTAAGTGAT & 3'-UTR \\
\hline Optineurin (1) & GCACGGCATTGTCTAAATATA & CDS \\
\hline Optineurin (2) & GCCATGAAGCTAAATAATCAA & CDS \\
\hline p62 & CCGAATCTACATTAAAGAGAA & CDS \\
\hline NBR1 (1) & GCCAGGAACCAAGTTTATCAA & CDS \\
\hline NBR1 (2) & CCATCCTACAATATCTGTGAA & CDS \\
\hline VCP (1) & ACCGTCCCAATCGGTTAATTG & CDS \\
\hline VCP (2) & AGATCCGTCGAGATCACTTTG & CDS \\
\hline
\end{tabular}




\begin{tabular}{|l|l|}
\hline $\begin{array}{l}\text { NDP52 C443K \& } \\
\text { C443K/V136S } \\
\text { BamHI-Forward }\end{array}$ & 5' TAAGCAGGATCCGCCACCATGGTGAGCAAG 3' \\
\hline $\begin{array}{l}\text { NDP52 C443K \& } \\
\text { C443K/V136S } \\
\text { EcoRI-Reverse }\end{array}$ & 5' TAAGCAGAATTCCAGAGAGAGTGTTTGAACACGT 3' \\
\hline
\end{tabular}

Table 5: Antibodies

\begin{tabular}{|c|c|c|c|c|}
\hline Antibody & Species & $\begin{array}{l}\text { Vendor/Catalogue } \\
\#\end{array}$ & Application & Dilution \\
\hline Hedls & Mouse & Santa Cruz sc-8418 & $\begin{array}{l}\text { Immunofluorescence } \\
\text { Immunoblot }\end{array}$ & $\begin{array}{l}1: 1000 \\
1: 1000\end{array}$ \\
\hline KapB & Rabbit & $\begin{array}{l}\text { A generous gift from } \\
\text { Don Ganem }\end{array}$ & Immunofluorescence & $1: 1000$ \\
\hline NDP52 & Rabbit & CST 60732 & Immunoblot & $1: 1000$ \\
\hline p62 & Rabbit & CST 7695 & Immunoblot & $1: 1000$ \\
\hline Dcpla & Mouse & CST 15365 & Immunoblot & $1: 500$ \\
\hline DDX6 & Rabbit & Bethyl A300-461 & Immunoblot & $1: 1000$ \\
\hline MK2 & Rabbit & CST 12155 & Immunofluorescence & $1: 1000$ \\
\hline LC3B & Rabbit & CST 2775 & $\begin{array}{l}\text { Immunofluorescence } \\
\text { Immunoblot }\end{array}$ & $\begin{array}{l}1: 200 \\
1: 1000\end{array}$ \\
\hline $\operatorname{Atg} 5$ & Rabbit & CST 2630 & Immunoblot & $1: 1000$ \\
\hline Atg14 & Rabbit & CST 96752 & Immunoblot & $1: 1000$ \\
\hline OPTN & Rabbit & Abcam ab23666 & Immunoblot & $1: 1000$ \\
\hline Xrn1 & Rabbit & Abcam ab231197 & Immunoblot & $1: 1000$ \\
\hline VCP & Rabbit & CST 2649 & Immunoblot & $1: 1000$ \\
\hline NBR1 & Rabbit & CST 9891 & Immunoblot & $1: 1000$ \\
\hline
\end{tabular}




\begin{tabular}{|l|l|}
\hline Primer & Primer Sequence \\
\hline HPRT-1- Forward & 5' CTTTCCTTGGTCAGGCAGTATAA 3' \\
\hline HPRT-2 - Reverse & 5' AGTCTGGCTTATATCCAACACTTC 3' \\
\hline 18S - Forward & 5' TTCGAACGTCTGCCCTATCAA 3' \\
\hline 18S - Reverse & 5' GATGTGGTAGCCGTTTCTCAGG 3' \\
\hline IL-6 - Forward & 5' GAAGCTCTATCTCGCCTCCA 3' \\
\hline IL-6 - Reverse & 5' TTTTCTGCCAGTGCCTCTTT 3' \\
\hline CXCL8 - Forward & 5' AAATCTGGCAACCCTAGTCTG 3' \\
\hline CXCL8 - Reverse & 5' GTGAGGTAAGATGGTGGCTAAT 3' \\
\hline IL-1 $\beta$ - Forward & 5' CTCTCACCTCTCCTACTCACTT 3' \\
\hline IL-1 $\beta$ - Reverse & 5' TCAGAATGTGGGAGCGAATG 3' \\
\hline COX-2 - Forward & 5' CCCTTGGGTGTCAAAGGTAA 3' \\
\hline COX-2 - Reverse & 5' GCCCTCGCTTATGATCTGTC 3' \\
\hline
\end{tabular}




\section{Supplemental Figure Legends}

1055

1056

1057

1058

1059

1060

1061

1062

1063

1064

1065

1066

1067

1068

1069

1070

1071

1072

1073

1074

1075

1076

\section{Figure S1: KapB expression promotes PB disassembly but does not prevent PB assembly.}

HeLa cells expressing a doxycycline-inducible GFP-Dcpla were used to determine whether KapB prevented granule assembly or promoted disassembly. A: HeLa cells were transfected with either KapB or an empty vector control prior to inducing expression of GFP-Dcpla with doxycycline $(1 \mu \mathrm{g} / \mathrm{mL})$. Cells were fixed $12 \mathrm{~h}$ post-induction and immunostained for Hedls (PBs, red) and KapB (blue). Scale bar=20 $\mu \mathrm{m}$. B: GFP-Dcpla expression was induced with doxycycline $(1 \mu \mathrm{g} / \mathrm{mL})$ in HeLa cells prior to transfection with either KapB or an empty vector control. Cells were fixed $12 \mathrm{~h}$ post-transfection and immunostained for Hedls (PBs, red) and KapB (blue). Scale bar $=20 \mu \mathrm{m}$. C: HUVECs were transduced with recombinant lentiviruses expressing either Kaposin B (KapB) or an empty vector control and selected with blasticidin (5 $\mu \mathrm{g} / \mathrm{mL})$. Cells were treated with sodium arsenite $(0.25 \mathrm{mM})$ or a vehicle control for 30 min prior to fixation in $4 \%$ paraformaldehyde and permeabilization in $0.1 \%$ Triton $\mathrm{X}-100$. Scale bar $=20$ $\mu \mathrm{m}$.

\section{Figure S2: Canonical autophagy knockdown prevents KapB-mediated PB disassembly.} A\&B: HUVECs were sequentially transduced: first with recombinant lentiviruses expressing either shRNAs targeting Atg5 or Atg14 (shAtg5, shAtg14) or a non-targeting control (NS) and selected with puromycin $(1 \mu \mathrm{g} / \mathrm{mL})$, and second with either $\mathrm{KapB}$ or an empty vector control and selected with blasticidin $(5 \mu \mathrm{g} / \mathrm{mL})$. Samples were lysed in 2x Laemmli and resolved by SDS-

PAGE. Samples were immunoblotted for Atg5 (A) or Atg14 (B). For Atg5 (A) samples were quantified by normalizing Atg5 protein levels to the total protein in each lane using Image Lab (Biorad) and then to Vector NS. Results were plotted in GraphPad, a 2-way ANOVA was 
1077 performed, \pm SEM; $\mathrm{n}=3, * * *=\mathrm{P}<0.001$. C: Atg5 +/+ (WT) and -/- (KO) MEFs were transduced as

1078 in A and harvested in 2x Laemmli buffer before being resolved by SDS-PAGE. Samples were

1079 probed for LC3, a representative blot is shown. D: Atg5 +/+ and -/- MEFs were transduced with

1080 recombinant viruses expressing $\mathrm{KapB}$ or an empty vector control and selected with blasticidin (5

$1081 \mu \mathrm{g} / \mathrm{mL}$ ). Samples were fixed in 4\% paraformaldehyde and permeabilized in $0.1 \%$ Triton X-100.

1082 Immunofluorescence was performed for Hedls (PBs, white) and DAPI (nuclei, blue). Scale

1083 bar $=20 \mu \mathrm{m}$. Hedls puncta were counted using CellProfiler and normalized to the number of

1084 nuclei, results were plotted in GraphPad and a 2-way ANOVA was performed with a Šidák’s

1085 multiple comparison test, $\pm \mathrm{SEM} ; \mathrm{n}=3, *=\mathrm{P}<0.05, * *=\mathrm{P}<0.01$.

1086 Figure S3: Canonical autophagy shRNA silencing in HeLa cells. A\&B: HeLas were

1087 transduced with recombinant lentiviruses expressing either shRNAs targeting Atg5 or Atg14

1088 (shAtg5, shAtg14) or a non-targeting control (NS) and selected with puromycin $(1 \mu \mathrm{g} / \mathrm{mL}) \mathrm{prior}$

1089 to transfection with KapB or an empty vector for luciferase assays. Samples were lysed in $2 \mathrm{x}$

1090 Laemmli buffer and resolved by SDS-PAGE before immunoblotting with Atg5 (A) or Atg14 (B).

1091 Representative blots are shown.

1092 Figure S4: Selective autophagy receptor knockdown in HUVECs reveals that OPTN and

1093 p62 are not required for KapB-mediated PB disassembly. A\&B: HUVECs were transduced

1094 with shRNAs targeting VCP, NBR1, or a non-targeting control (NS) and selected with

1095 puromycin $(1 \mu \mathrm{g} / \mathrm{mL})$, then transduced with an empty vector control or KapB and selected with

1096 blasticidin $(5 \mu \mathrm{g} / \mathrm{mL})$. Samples were lysed in 2x Laemmli buffer, resolved by SDS-PAGE, and

1097 immunoblotted for NBR1 (A) and VCP (B). Representative blots are shown, successful VCP

1098 knockdown was lethal, while NBR1 knockdown was not successful. C: HUVECs were

1099 transduced with shRNAs targeting NDP52 or a non-targeting control (NS) and selected with 
1100 puromycin $(1 \mu \mathrm{g} / \mathrm{mL})$, then transduced with an empty vector control or KapB and selected with

1101 blasticidin $(5 \mu \mathrm{g} / \mathrm{mL})$. Samples were lysed in 2x Laemmli buffer, resolved by SDS-PAGE, and

1102 immunoblotted for NDP52. D\&E: HUVECs were transduced with shRNAs targeting p62,

1103 OPTN, or a non-targeting control (NS) and selected with puromycin $(1 \mu \mathrm{g} / \mathrm{mL})$, then transduced

1104 with an empty vector control or $\mathrm{KapB}$ and selected with blasticidin $(5 \mu \mathrm{g} / \mathrm{mL})$. Samples were

1105 lysed in 2x Laemmli buffer and resolved by SDS-PAGE. Samples were immunoblotted for p62

1106 (D) and OPTN (E), representative blots are shown. F: HUVECs were transduced as in D and E.

1107 Coverslips were fixed in 4\% paraformaldehyde, permeabilized in $0.1 \%$ Triton X-100 and

1108 immunostained for Hedls (PBs; white), DAPI (nuclei, blue). Scale bar=20 $\mu \mathrm{m}$. G: HUVECs were

1109 transduced with recombinant lentiviruses targeting NDP52 or a non-targeting control (NS) and

1110 selected with puromycin $(1 \mu \mathrm{g} / \mathrm{mL})$. Samples were lysed in $2 x$ Laemmli buffer, resolved by

1111 SDS-PAGE, and immunoblotted for NDP52 to confirm knockdown for paired Torin

1112 immunofluorescence experiments.

1114 Figure S5: shRNA silencing of selective autophagy receptors in HeLa cells. A, B\&C: HeLas

1115 were transduced with shRNAs targeting NDP52, OPTN, p62, or a non-targeting control (NS) and 1116 selected with puromycin $(1 \mu \mathrm{g} / \mathrm{mL})$ prior to transfection with KapB or an empty vector for

1117 luciferase assays. Samples were lysed in 2x Laemmli buffer, resolved by SDS-PAGE, and

1118 immunoblotted for NDP52 (A), p62 (B), and OPTN (C). Representative blots are shown. 
1122 targeting control (NS) and selected with puromycin $(1 \mu \mathrm{g} / \mathrm{mL})$, then co-transduced with an

1123 empty vector control and mCherry (mCh) or KapB and mCh. Samples were lysed in 2x

1124 Laemmli, resolved by SDS-PAGE, and immunoblotted for NDP52. B: HUVECs were

1125 sequentially transduced first with recombinant lentivirus expressing shDNP52 targeting the 3'-

1126 UTR of NDP52 or a NS control and selected with blasticidin $(5 \mu \mathrm{g} / \mathrm{mL})$, and second, with vector

1127 and one of the following: mCherry control (mCh), RFP-NDP52 wt, mCh-NDP52 C443K or

1128 mCh-NDP52 V136S/C443K. Coverslips were fixed with 4\% v/v paraformaldehyde,

1129 permeabilized with $0.1 \%$ Triton X-100, and were immunostained with Hedls (PBs, green). Scale

1130 bar $=20 \mu \mathrm{m}$. C: Hedls puncta were counted using CellProfiler and normalized to the number of

1131 nuclei, results were plotted in GraphPad.

1132 Figure S7: shRNA silencing of canonical and selective autophagy genes in MK2EE-

1133 expressing cells. A: HUVECs were transduced with shRNAs targeting Atg5 or a non-targeting

1134 control (NS) and selected with puromycin $(1 \mu \mathrm{g} / \mathrm{mL})$, then transduced with an empty vector

1135 control or KapB and selected with blasticidin $(5 \mu \mathrm{g} / \mathrm{mL})$. Samples were lysed in 2x Laemmli

1136 buffer, resolved by SDS-PAGE, and immunoblotted for Atg5. A representative blot is shown. B:

1137 HeLas were transduced with recombinant lentiviruses expressing either shRNAs targeting Atg5

1138 or a non-targeting control (NS) and selected with puromycin $(1 \mu \mathrm{g} / \mathrm{mL})$ prior to transfection with

1139 MK2EE or an empty vector for luciferase assays. Samples were lysed in 2x Laemmli buffer and

1140 resolved by SDS-PAGE before immunoblotting for Atg5. A representative blot is shown. C,

1141 D\&E: HUVECs were transduced with shRNAs targeting NDP52, p62, OPTN, or a non-targeting

1142 control (NS) and selected with puromycin $(1 \mu \mathrm{g} / \mathrm{mL})$, then transduced with an empty vector

1143 control or MK2EE and selected with blasticidin $(5 \mu \mathrm{g} / \mathrm{mL})$. Samples were lysed in 2x Laemmli

1144 buffer and resolved by SDS-PAGE. Samples were immunoblotted for NDP52 (C), p62 (D), and 
1145 OPTN (E), representative blots are shown. F: HUVECs were transduced with shRNAs as in

1146 D\&E. Coverslips were fixed, permeabilized, and immunostained for Hedls (PBs; white), DAPI

1147 (nuclei, blue). Scale bar=20 $\mu \mathrm{m} . \mathrm{G}, \mathrm{H} \& \mathrm{I}$ : HeLas were transduced with shRNAs targeting

1148 NDP52, OPTN, p62, or a non-targeting control (NS) and selected with puromycin $(1 \mu \mathrm{g} / \mathrm{mL})$,

1149 then transfected with an empty vector control or MK2EE for luciferase assays. Samples were

1150 lysed in 2x Laemmli buffer, resolved by SDS-PAGE, and immunoblotted for NDP52 (G), p62

1151 (H), and OPTN (I). Representative blots are shown. 
bio.Rxiv preprint doi: https://doi.org/10.1101/2021.02.07.430164; this version posted June 21, 2021. The copyright holder for this preprint (whichgld:enot certified by peer review) is the author/funder, who has granted bioRxiv a license to display the preprint in perpetuity. It is made available under aCC-BY 4.0 International license.

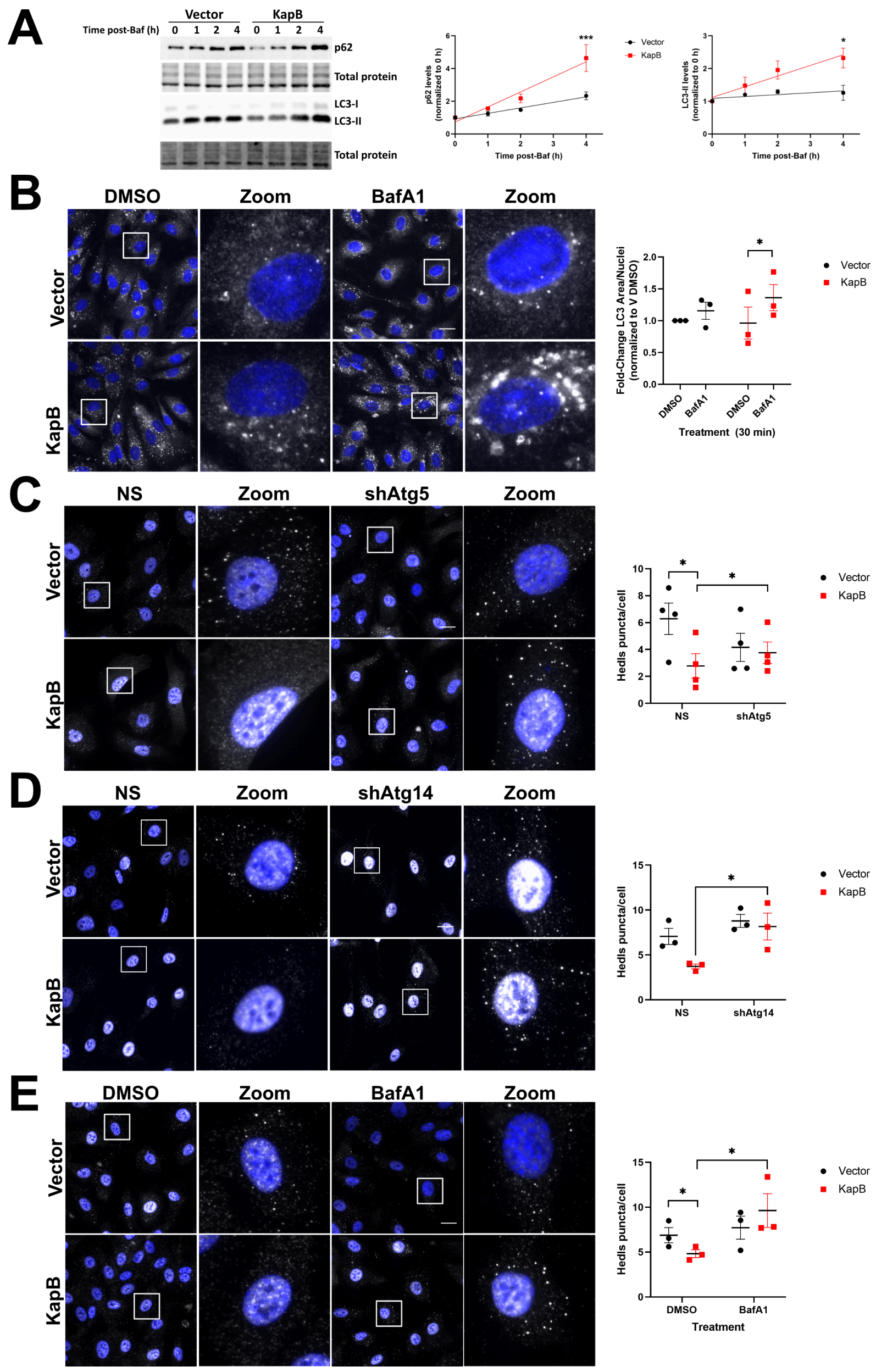


A

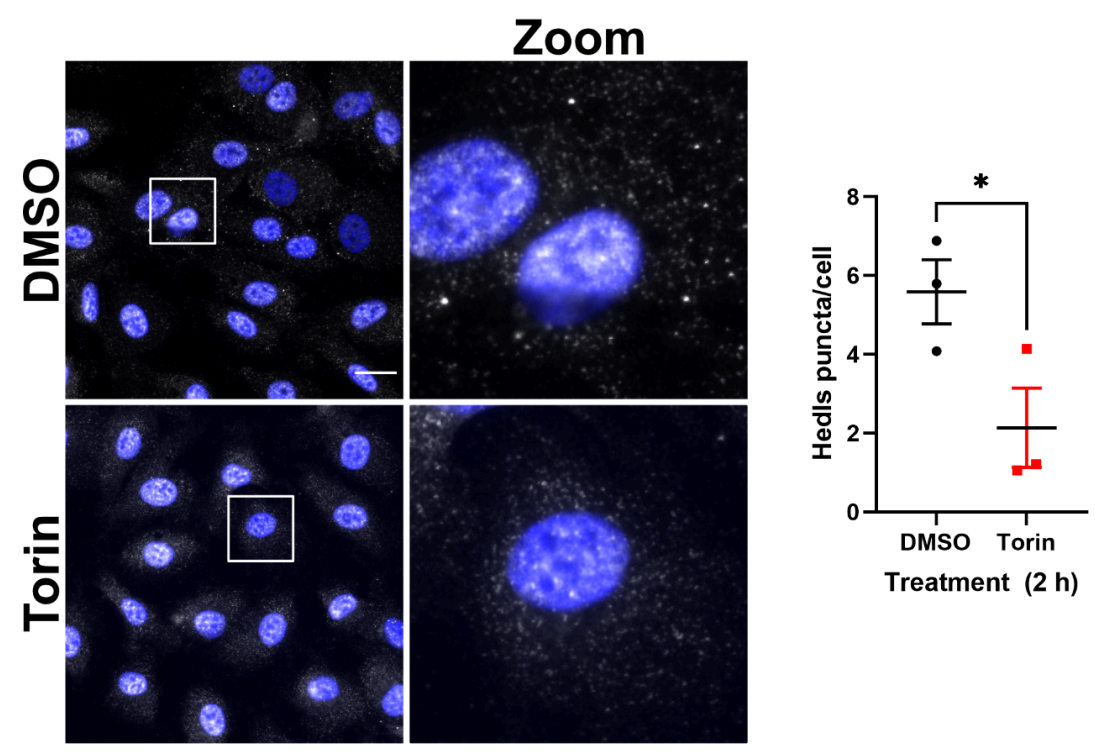

B

- Arsenite

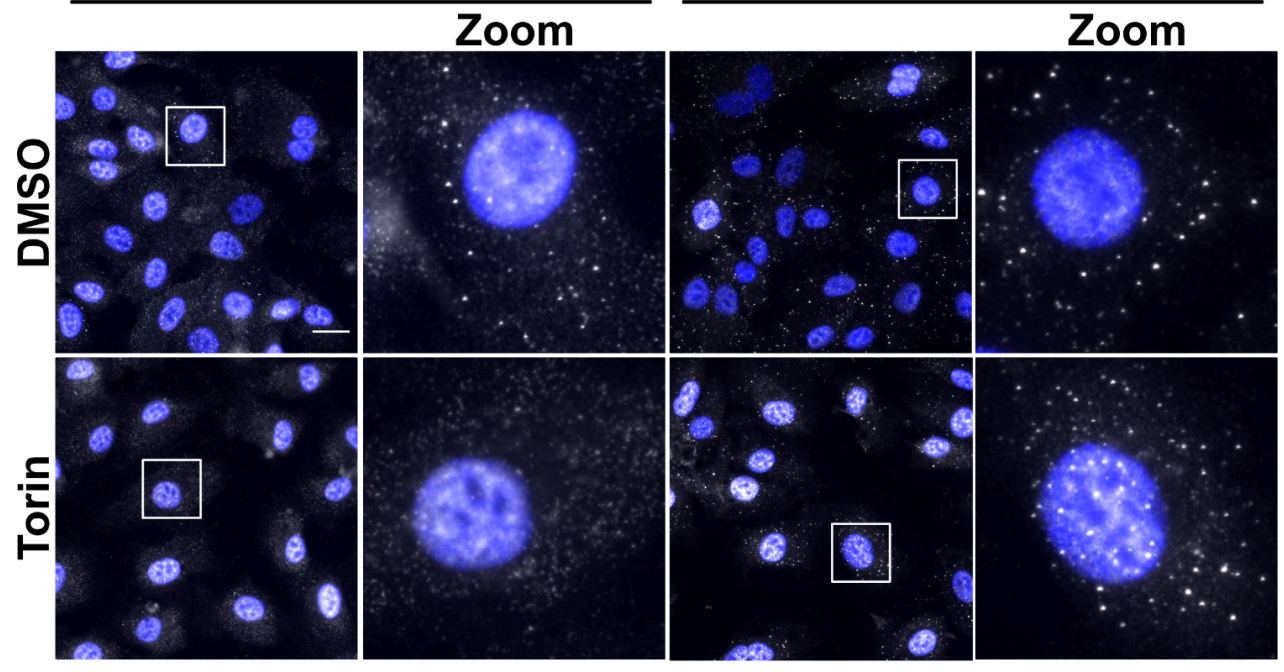

C

DMSO

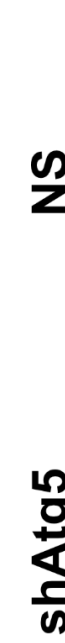

Zoom

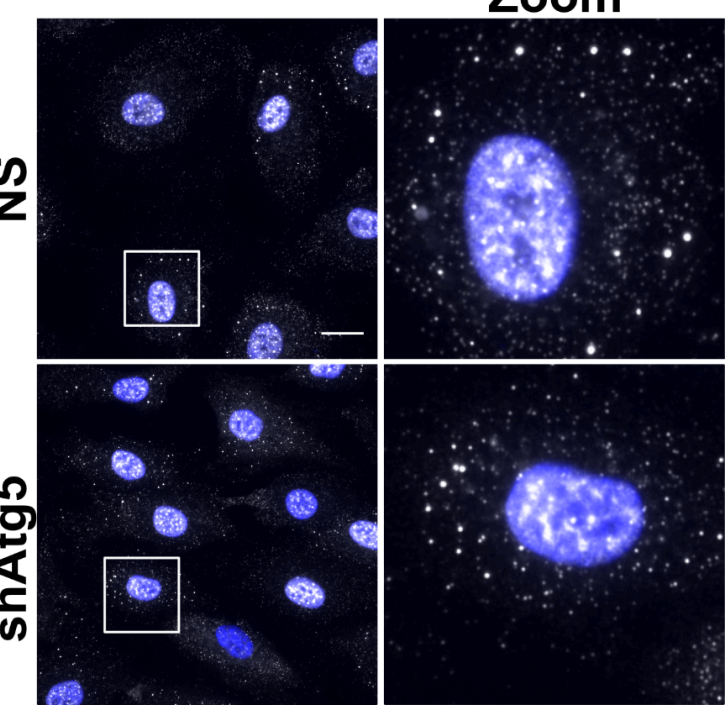

Torin

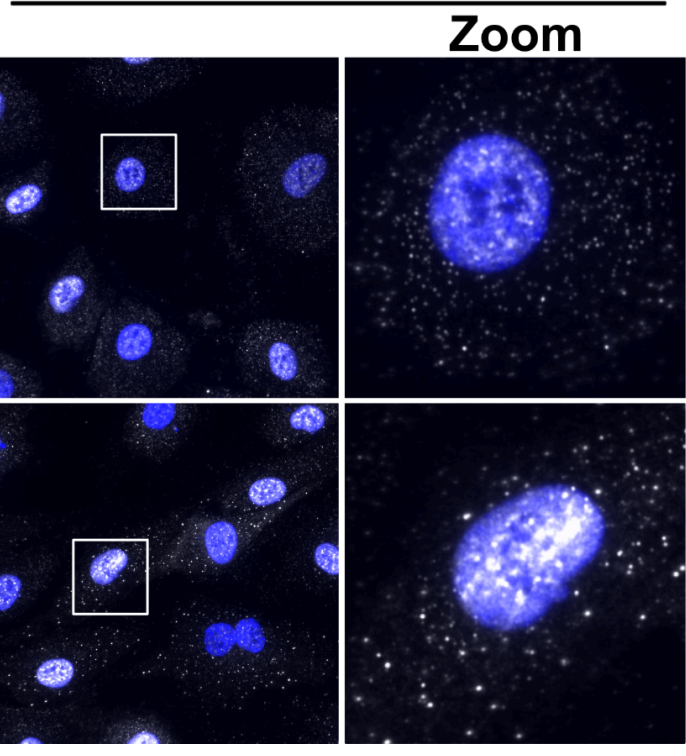

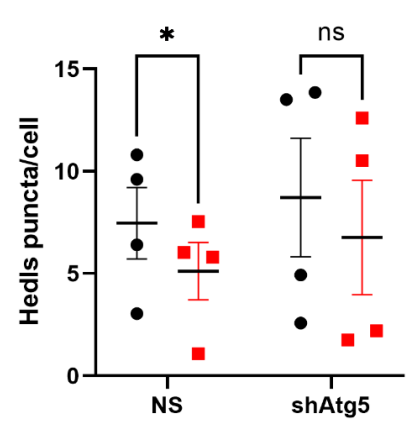

- DMSO

- Torin 
IL-6

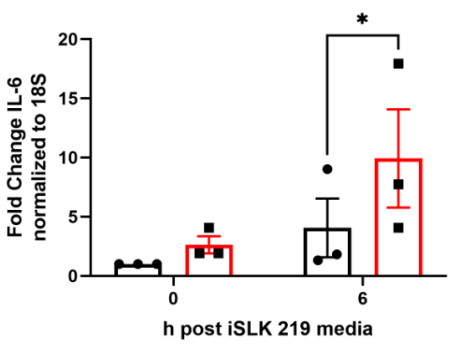

CXCL8

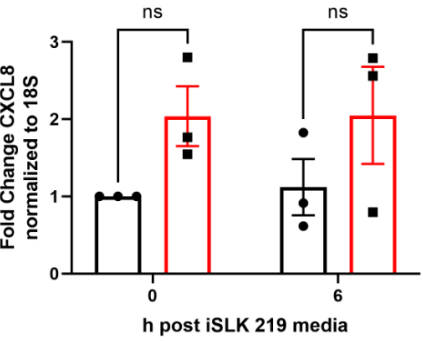

COX-2

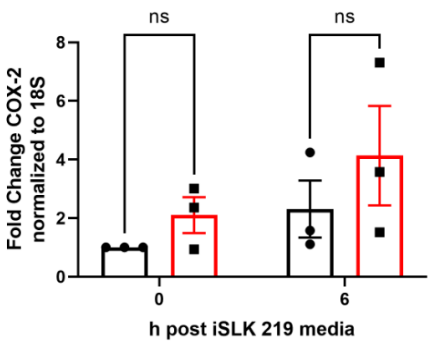

IL-1 $\beta$

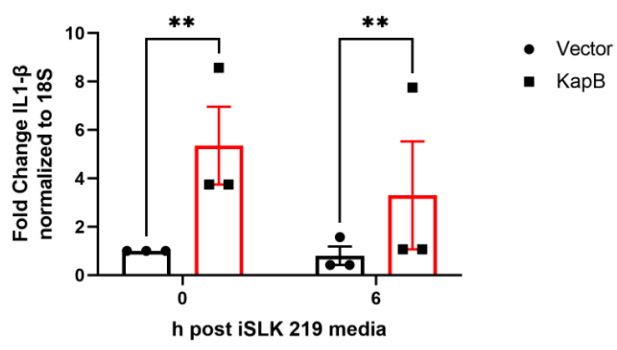

IL-6

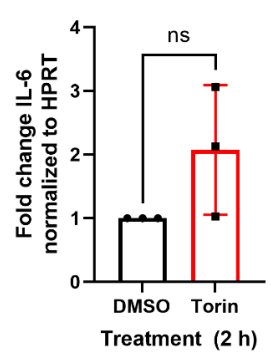

CXCL8

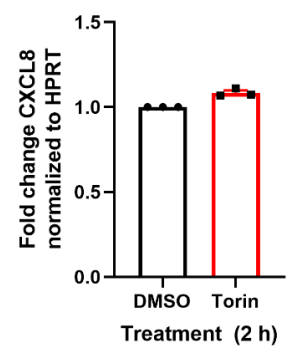

COX-2

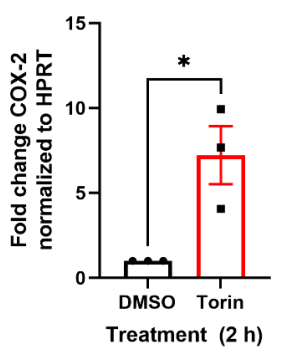

IL-1 $\beta$

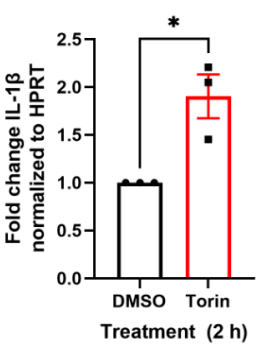

c

Vector

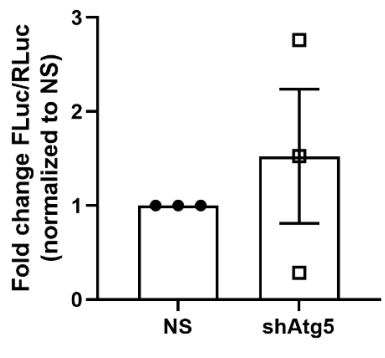

Vector
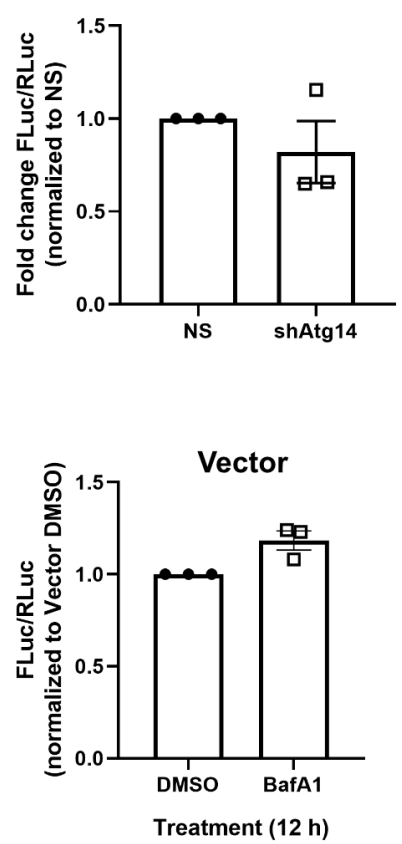

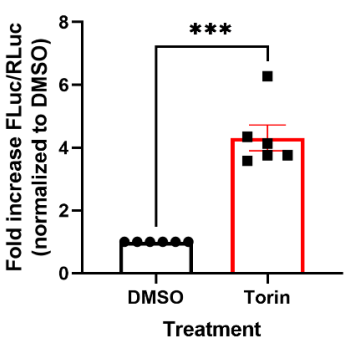

KapB

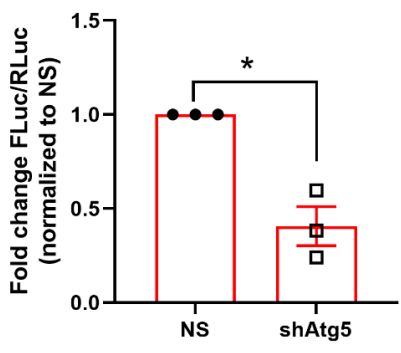

KapB
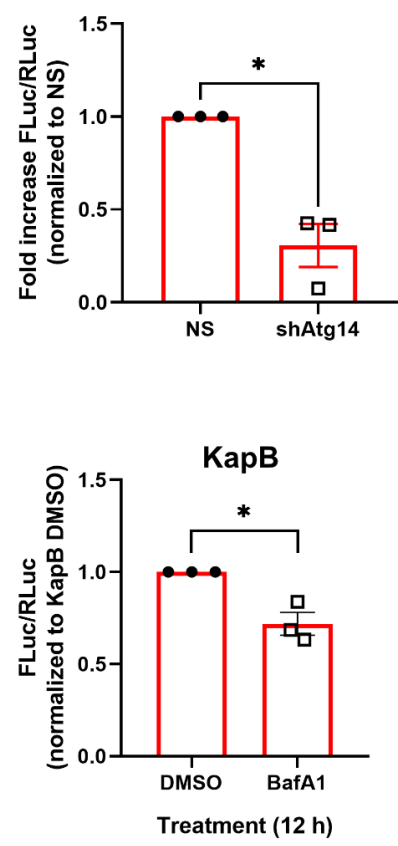
bioRxiv preprint doi: https://doi.org/10.1101/2021.02.07.430164; this version posted June 21, 2021. The copyright holder for this preprint (which was not certified by peer review) is the author/funder, who has granted bioRxiv a license to display the preprint in perpetuity. It is made Figure 4 available under aCC-BY 4.0 International license.
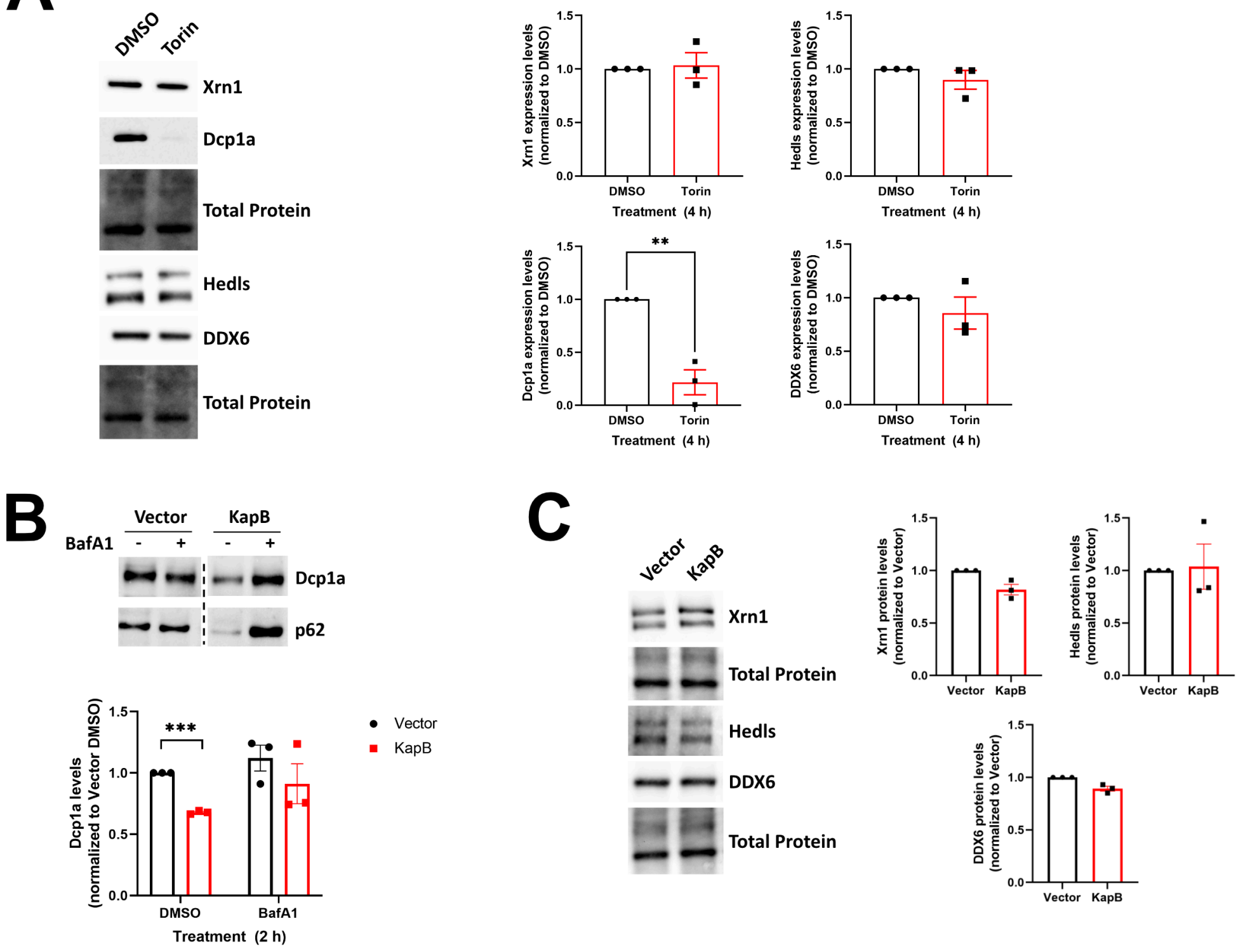

D
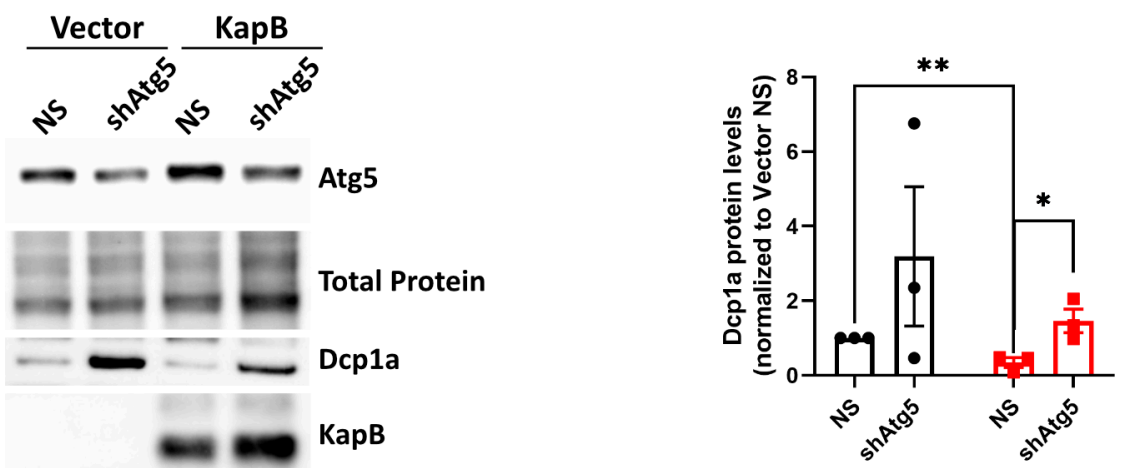

- Vector

- KapB

Total Protein 
bioRxiv preprint doi: https://doi.org/10.1101/2021.02.07.430164; this version posted June 21, 2021. The copyright holder for this preprint (which was not certified by peer review) is the author/funder, who has granted bioRxiv a license to display the preprint in perpetuity. It is made Figure 5 available under aCC-BY 4.0 International license.

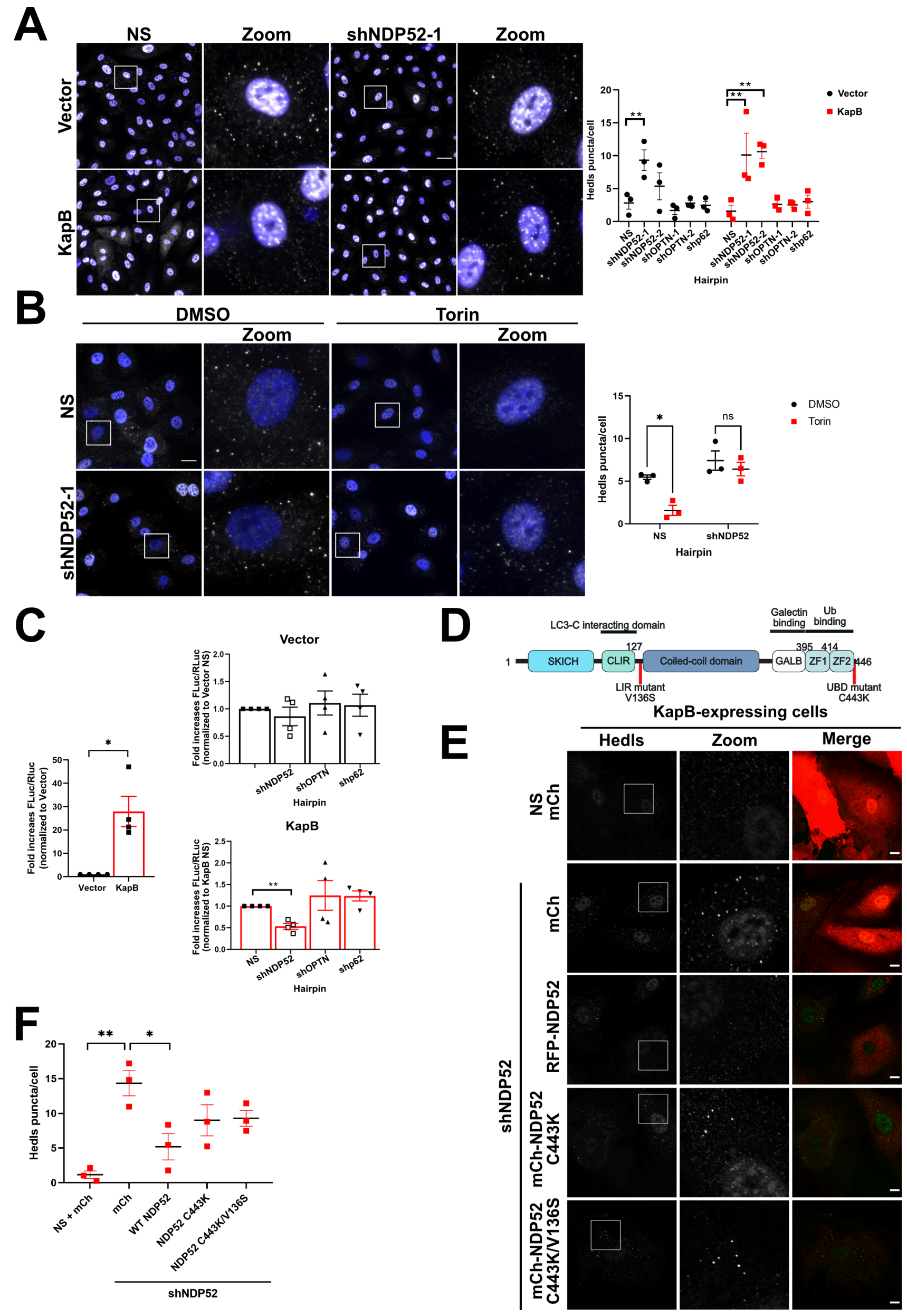


bioRxiv preprint doi: https://doi.org/10.1101/2021.02.07.430164; this version posted June 21, 2021. The copyright holder for this preprint (which nas not cextified by peer review) is the author/funder, who has granted bioRxiv a license to display the preprint in perpetuity. It is made available under aCC-BY 4.0 International license.

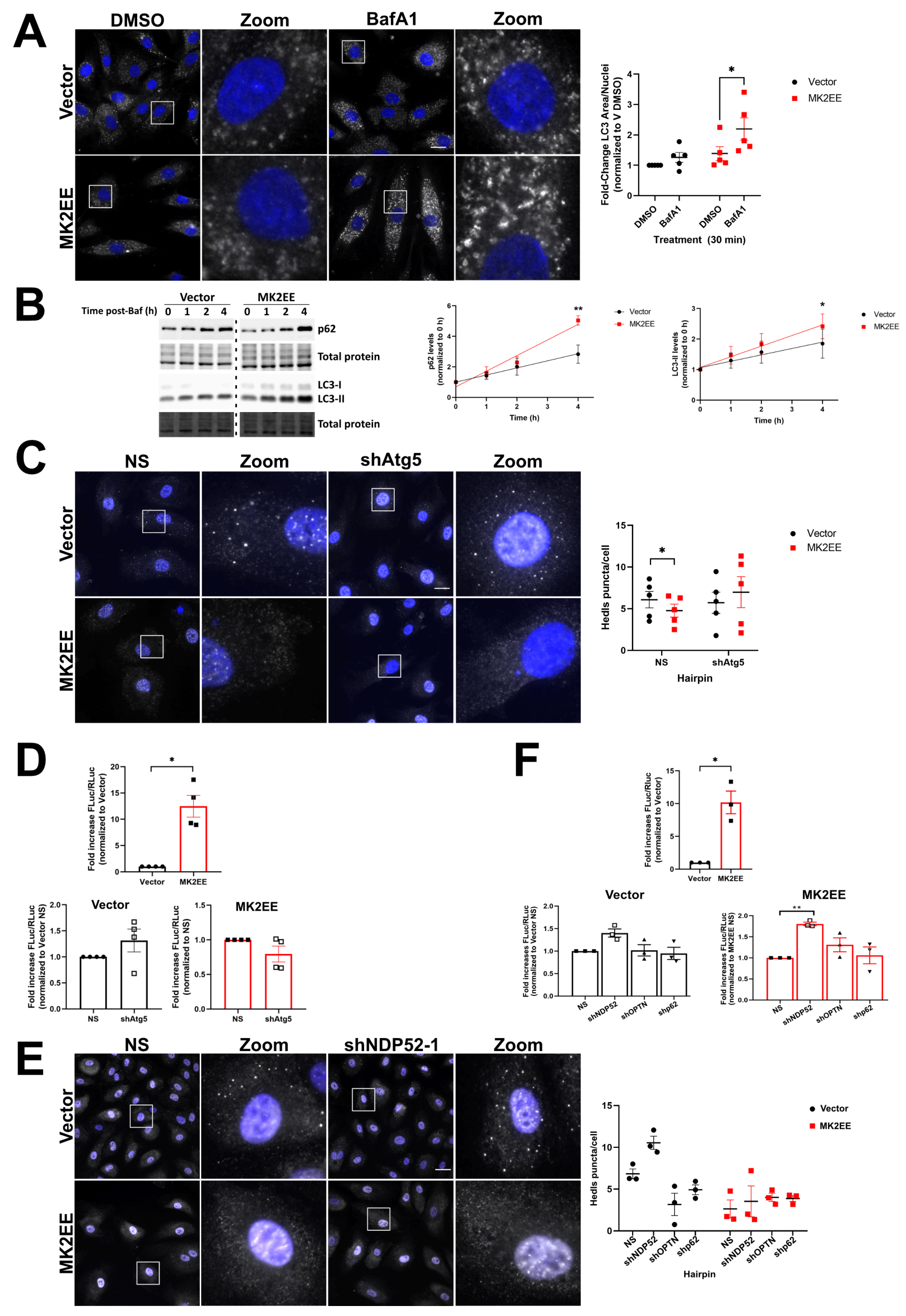


Figure 7

A

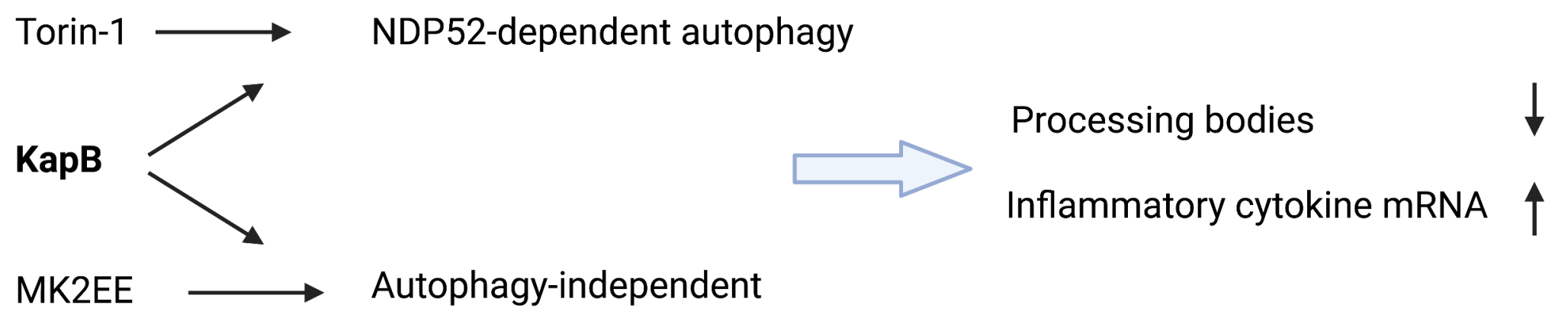

B

Processing Body
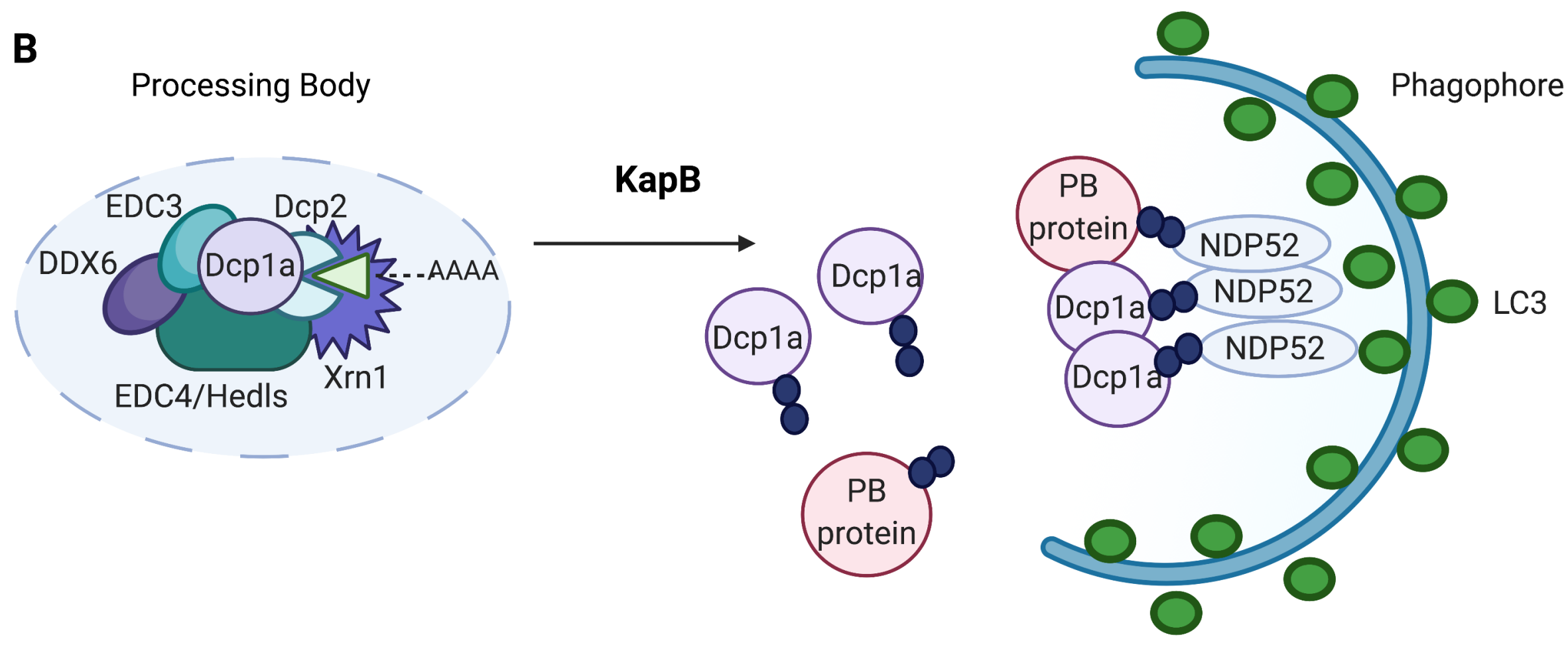

Fivhich wasnpt certified by peer review) is the author/funder, who has granted bioRxiv a license to display the preprint in perpetuity. It is made Figure $S$ available under aCC-BY 4.0 International license.

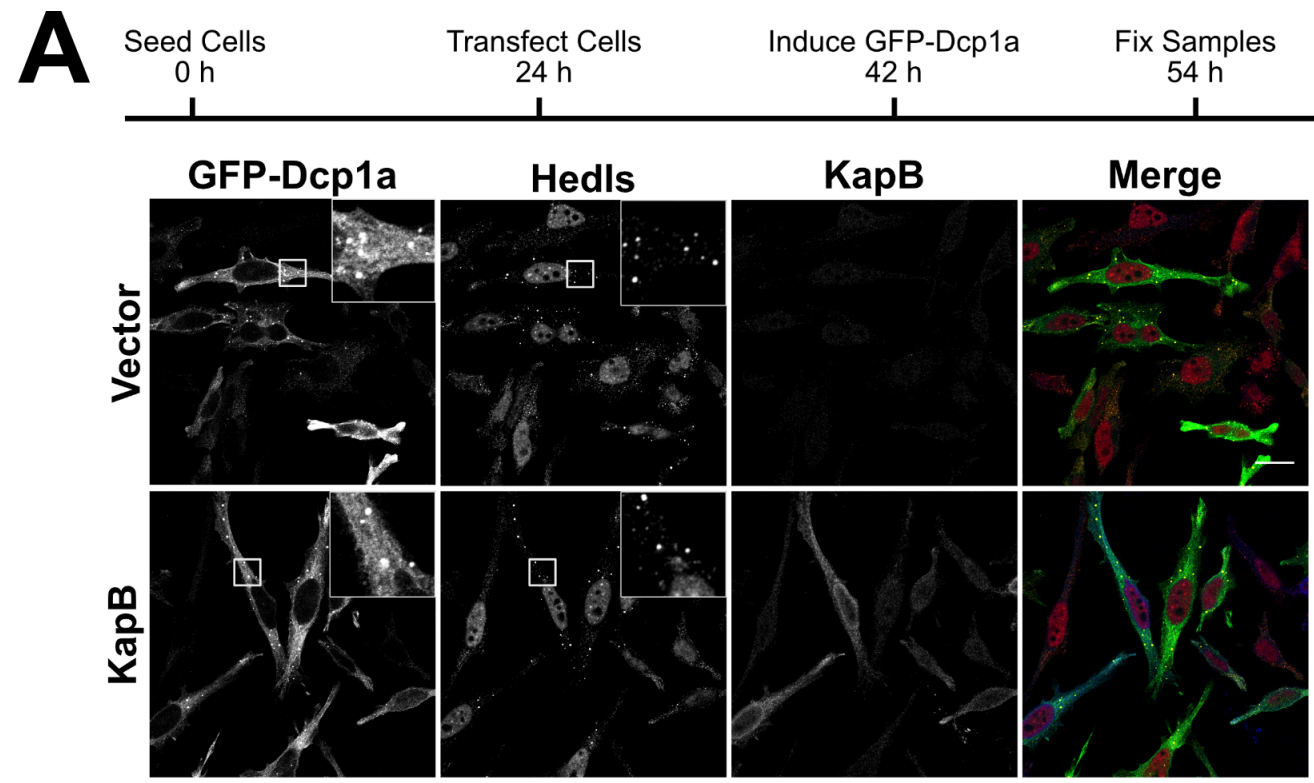

B
Seed Cells
Induce GFP-Dcp1a
$24 \mathrm{~h}$
Transfect Cells
$42 \mathrm{~h}$
Fix Samples
$54 \mathrm{~h}$

1

I

I

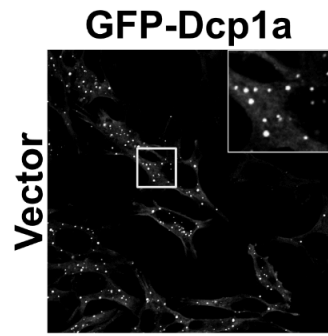

Hedls

KapB

Merge
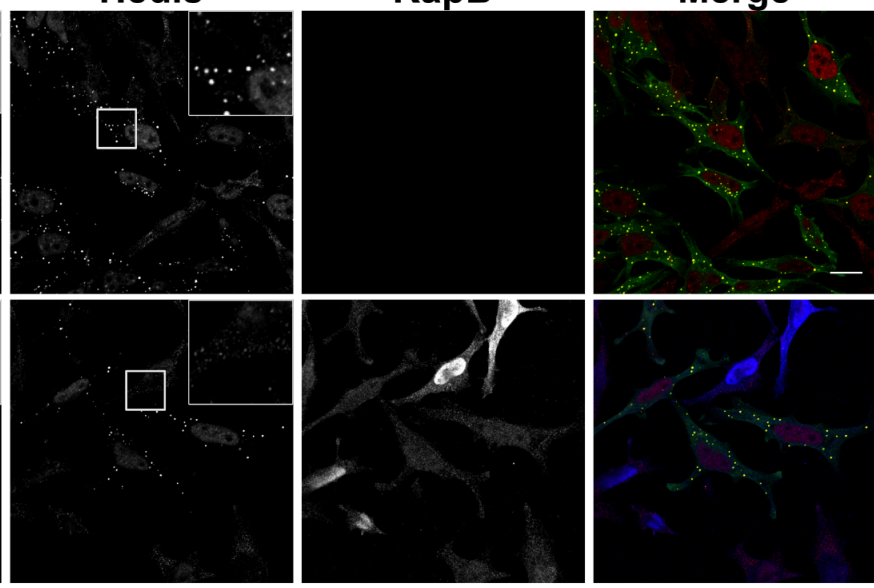

Vector

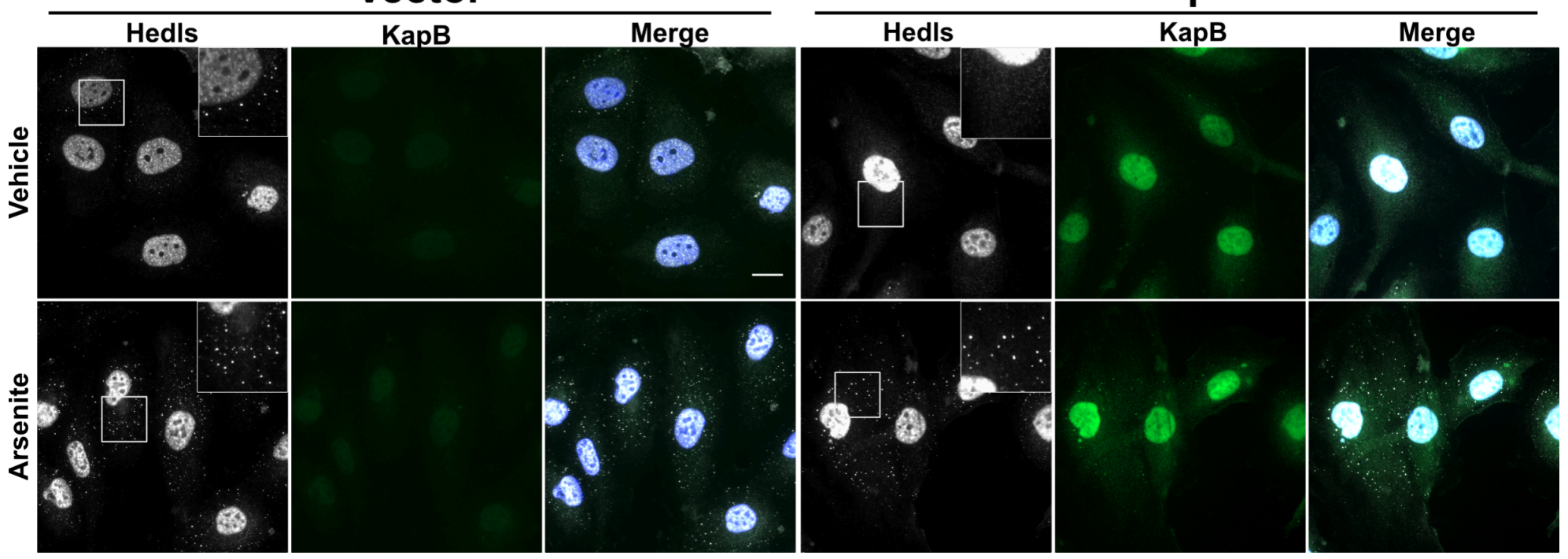


Figure S2
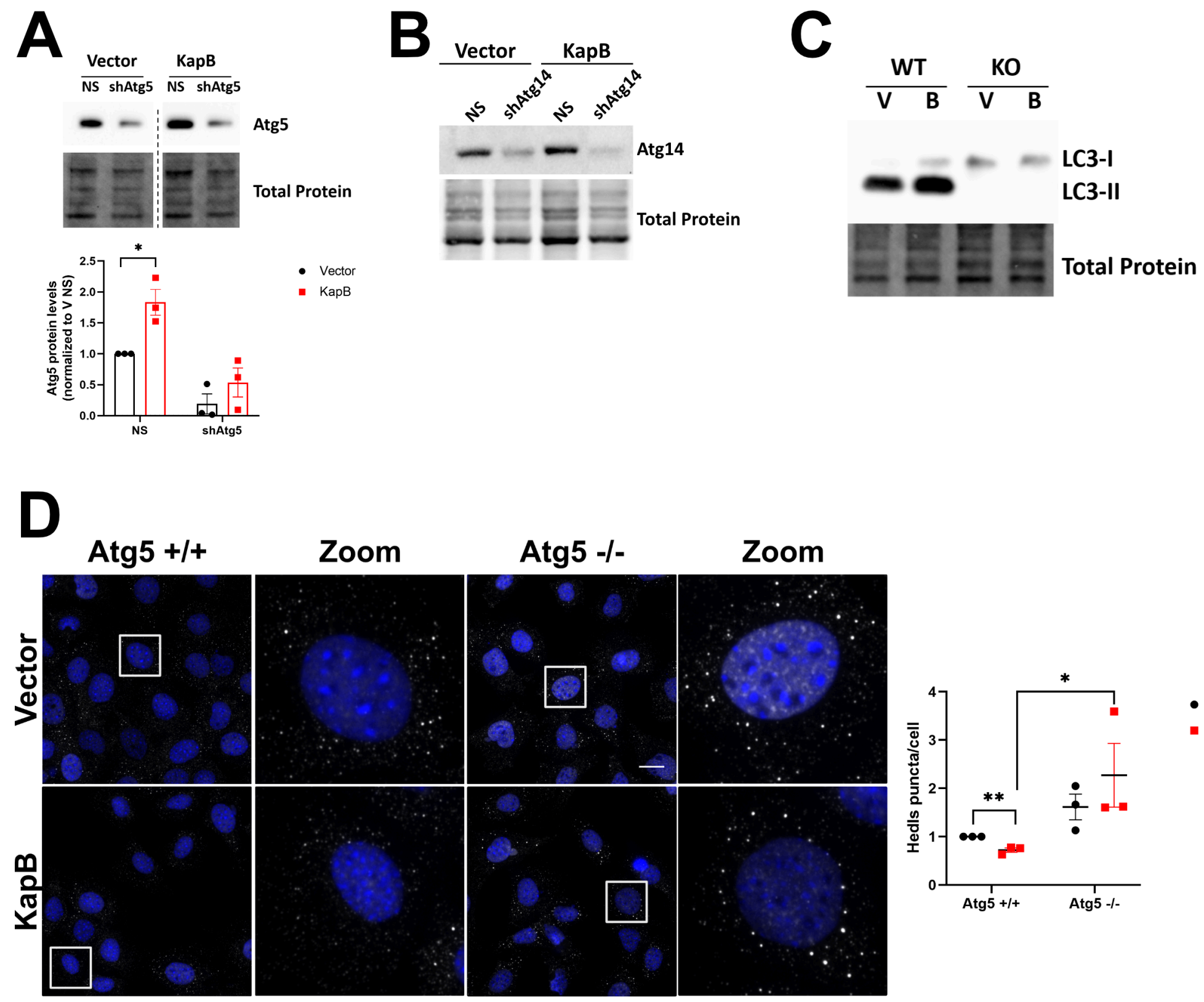

- Vector

- KapB 
bioRxiv preprint doi: $h$ ttps://doi.org/10.1101/2021.02.07.430164; this version posted June 21, 2021. The copyright holder for this preprint (which was not certified by peer review) is the author/funder, who has granted bioRxiv a license to display the preprint in perpetuity. It is made available under aCC-BY 4.0 International license.

\section{Figure S3}

A

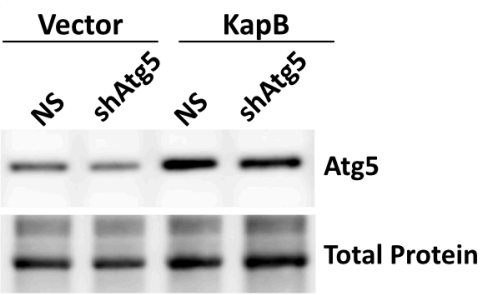

B

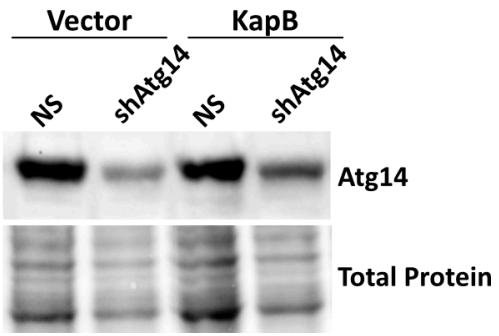


Figure S4 available under aCC-BY 4.0 International license.
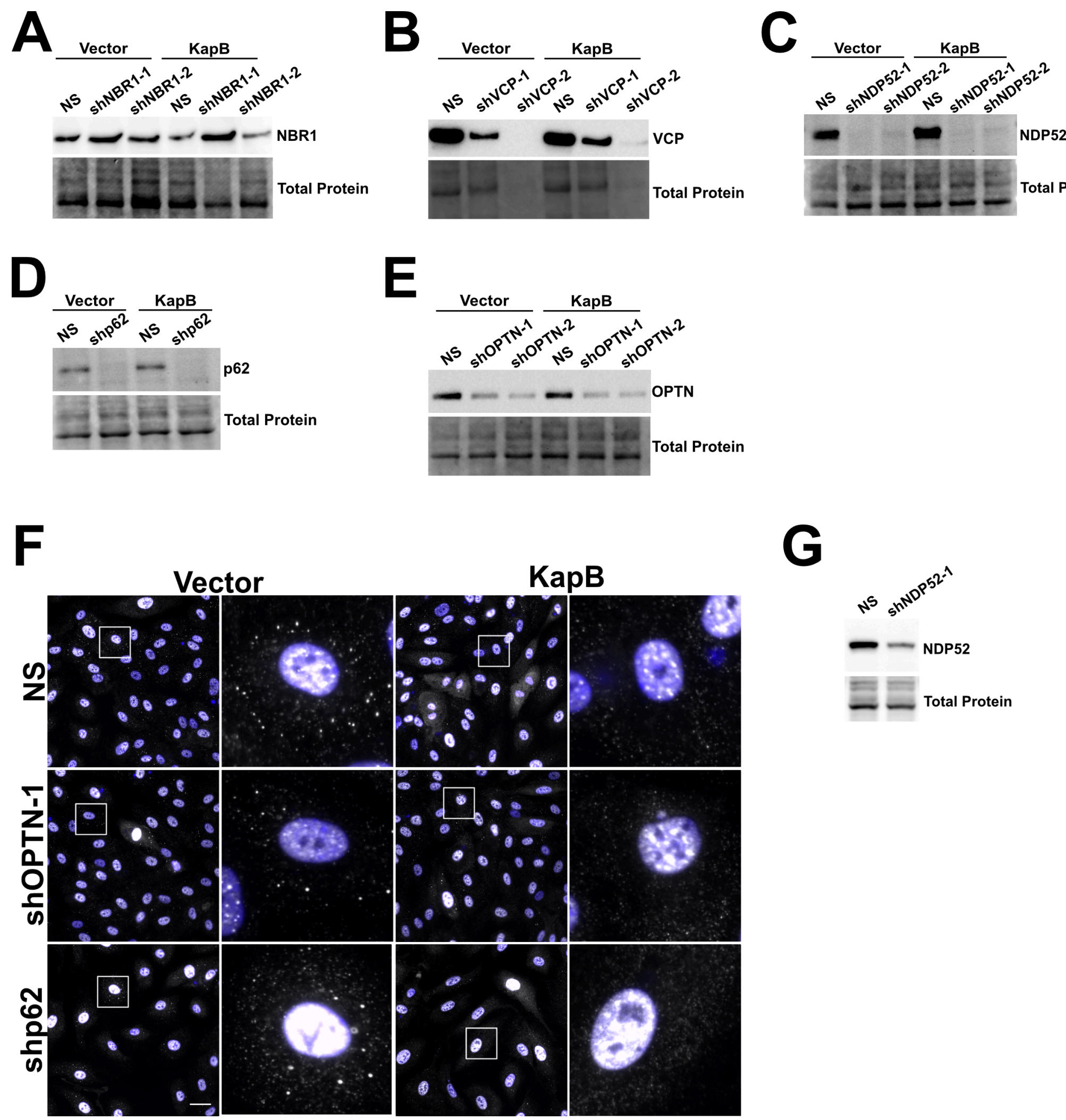
bioRxiv preprint doi: https://doi.org/10.1101/2021.02.07.430164; this version posted June 21, 2021. The copyright holder for this preprint (which was not certified by peer review) is the author/funder, who has granted bioRxiv a license to display the preprint in perpetuity. It is made

\section{Figure S5} available under aCC-BY 4.0 International license.

A

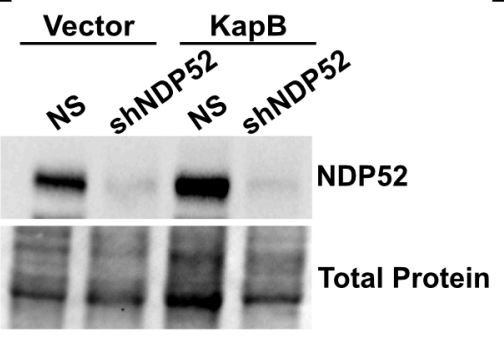

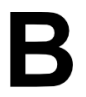

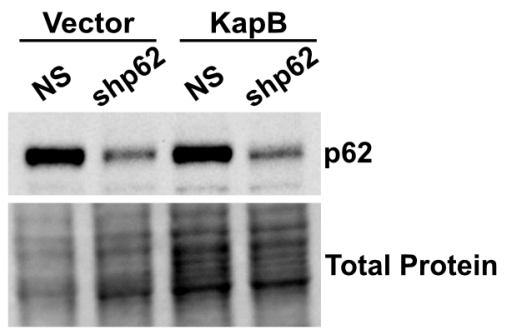

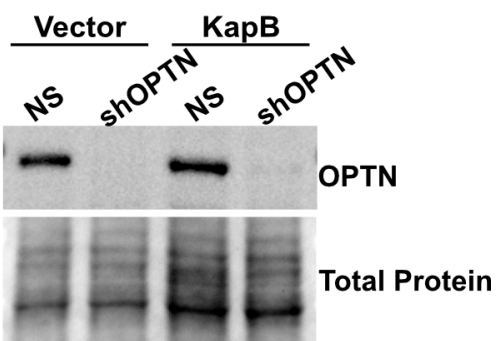




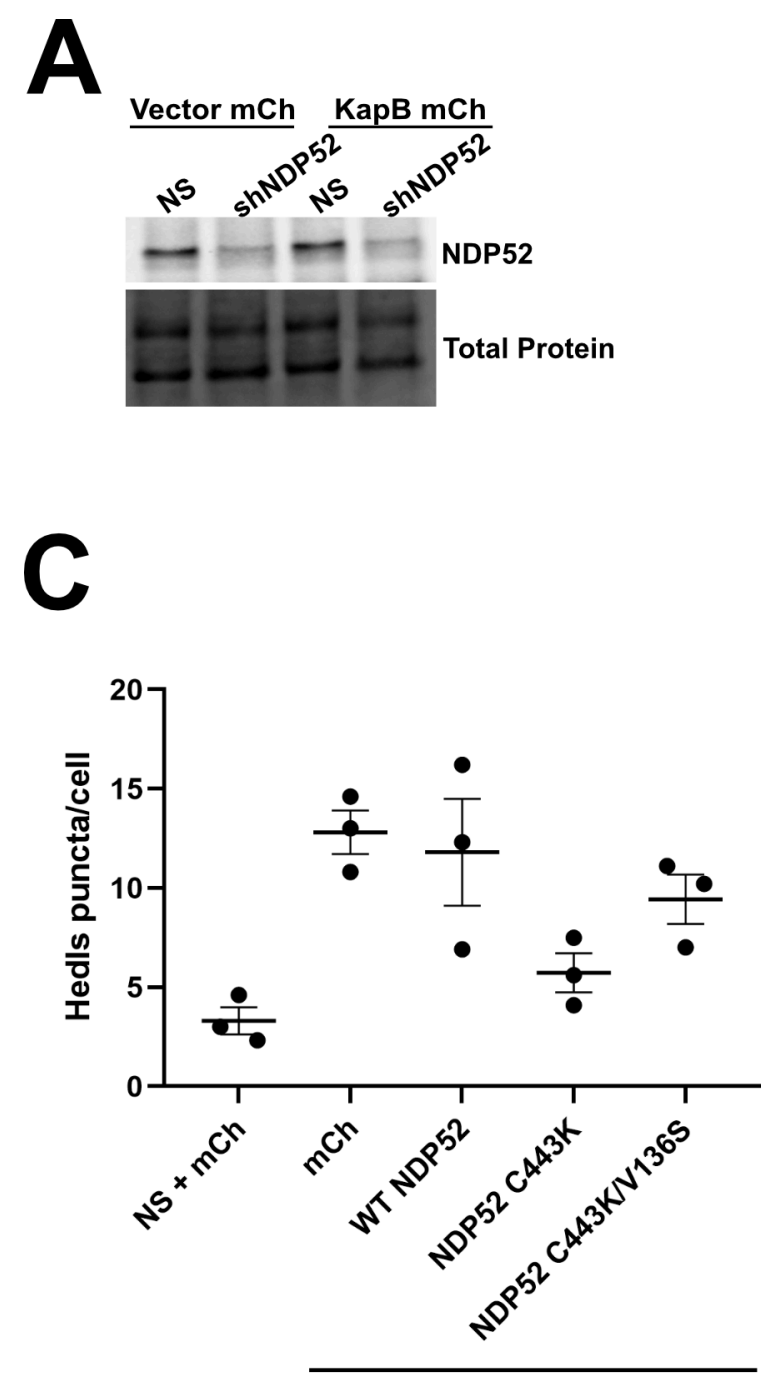

shNDP52
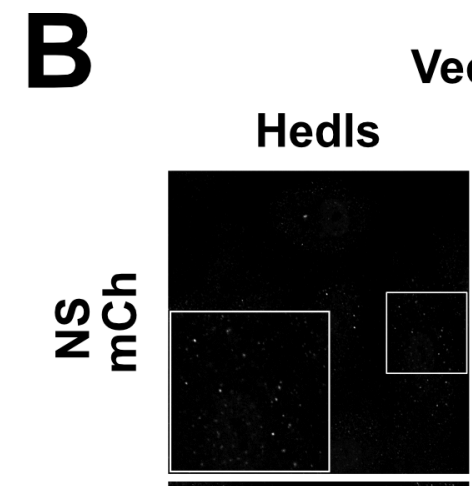

Vector
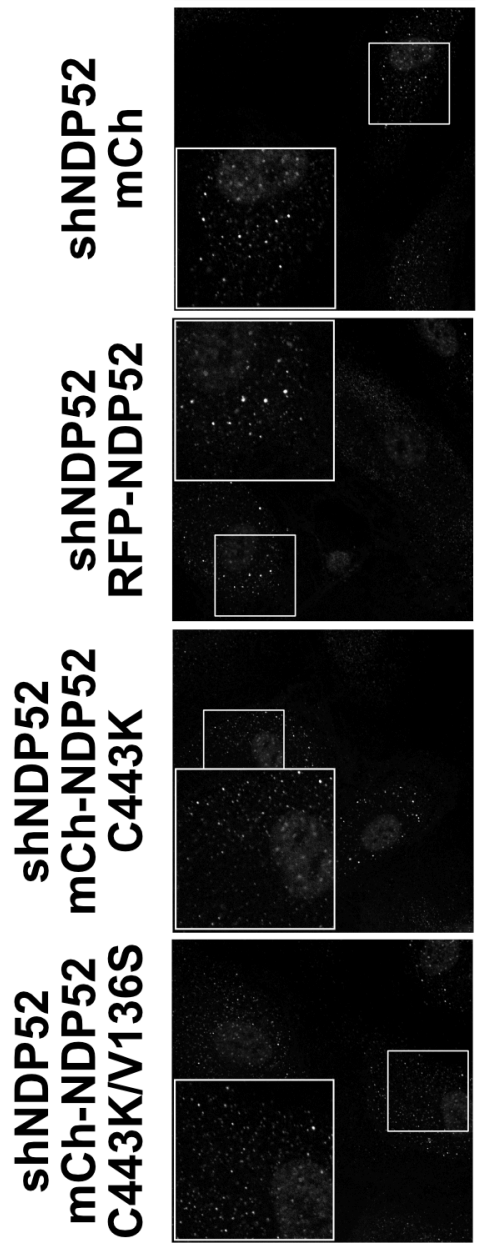

\section{Merge}
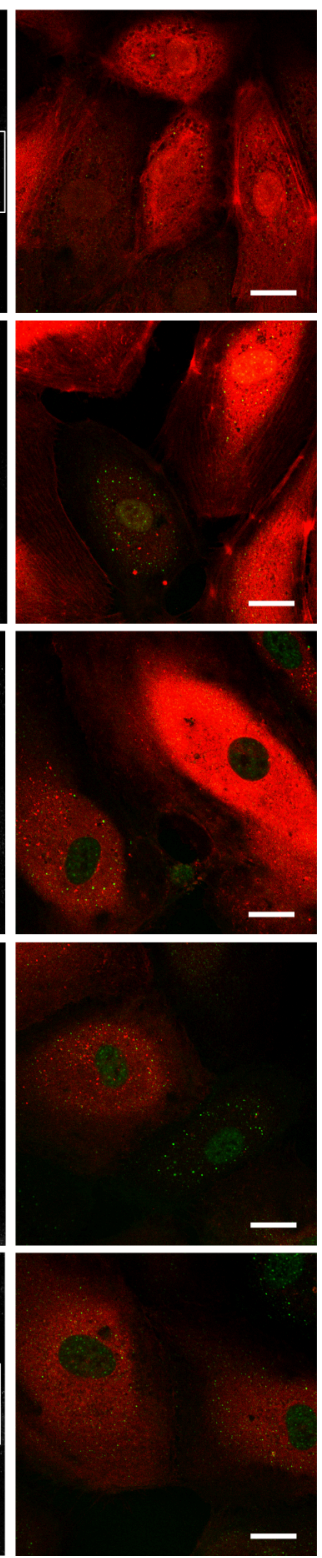
bioRxiv preprint doi: https://doi.org/10.1101/2021.02.07.430164; this version posted June 21, 2021. The copyright holder for this preprint (which was not certified by peer review) is the author/funder, who has granted bioRxiv a license to display the preprint in perpetuity. It is made Figure S7

A

Vector MK2EE

$\mathrm{sen}^{2}+-\operatorname{Atg5}$ available under aCC-BY 4.0 International license.

$\underline{-}+2$ Total Protein
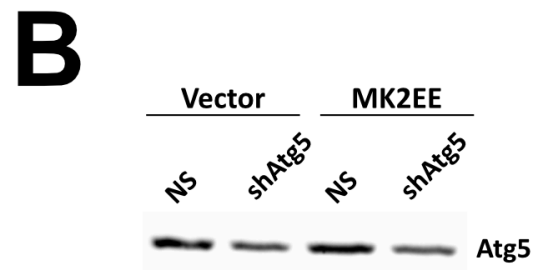

Total Protein

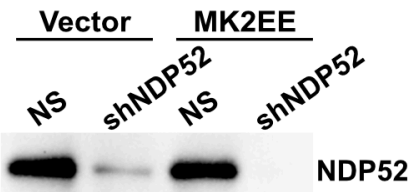

Total Protein
D

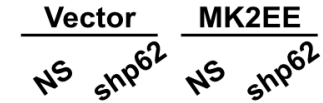

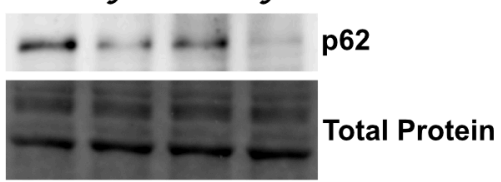

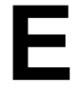

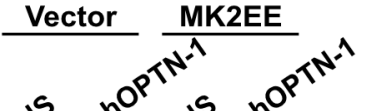

OPTN

Total Protein

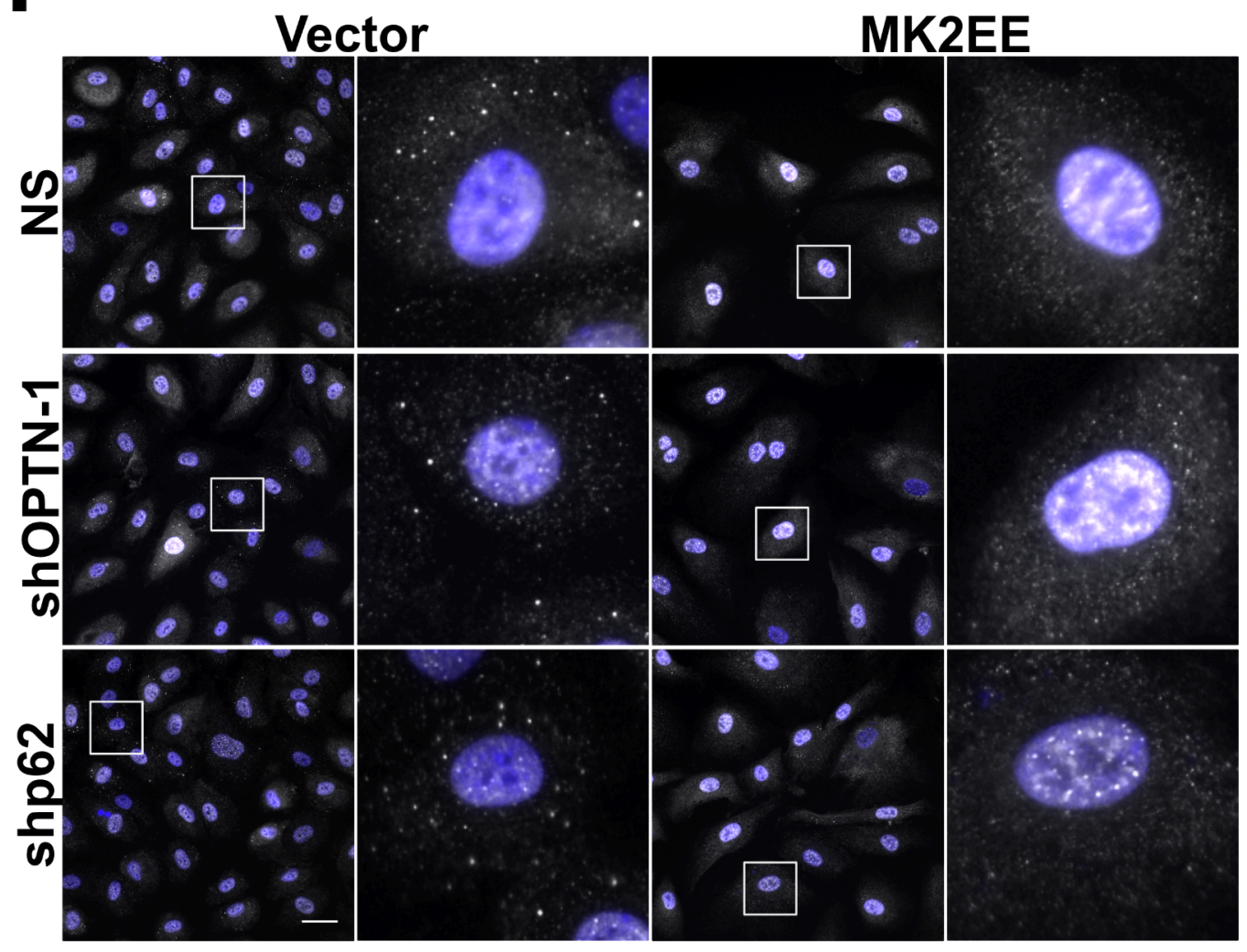

G
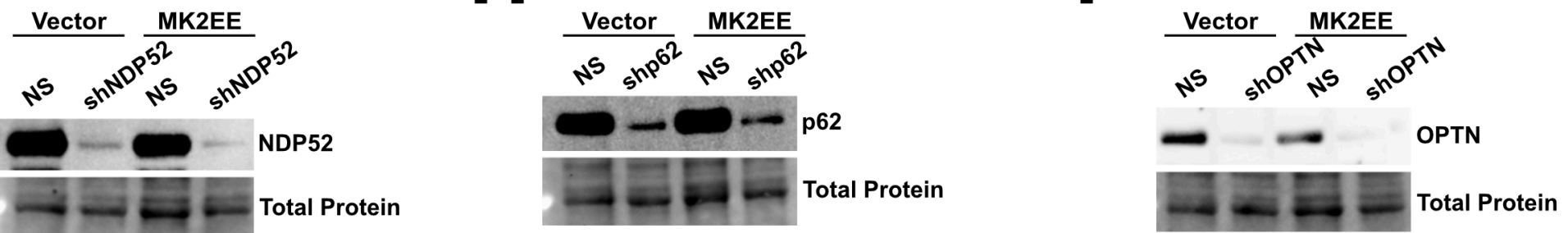